San Jose State University

SJSU ScholarWorks

Master's Theses

Master's Theses and Graduate Research

1995

\title{
Effects of the order of instructional activities on the attitudes and achievement of students working in cooperative groups
}

Christine Mack Campbell

San Jose State University

Follow this and additional works at: https://scholarworks.sjsu.edu/etd_theses

\section{Recommended Citation}

Campbell, Christine Mack, "Effects of the order of instructional activities on the attitudes and achievement of students working in cooperative groups" (1995). Master's Theses. 977.

DOI: https://doi.org/10.31979/etd.uva7-emps

https://scholarworks.sjsu.edu/etd_theses/977

This Thesis is brought to you for free and open access by the Master's Theses and Graduate Research at SJSU ScholarWorks. It has been accepted for inclusion in Master's Theses by an authorized administrator of SJSU ScholarWorks. For more information, please contact scholarworks@sjsu.edu. 


\section{INFORMATION TO USERS}

This manuscript has been reproduced from the microfilm master. UMI films the text directly from the original or copy submitted. Thus, some thesis and dissertation copies are in typewriter face, while others may be from any type of computer printer.

The quality of this reproduction is dependent upon the quality of the copy submitted. Broken or indistinct print, colored or poor quality illustrations and photographs, print bleedthrough, substandard margins, and improper alignment can adversely affect reproduction.

In the unlikely event that the author did not send UMI a complete manuscript and there are missing pages, these will be noted. Also, if unauthorized copyright material had to be removed, a note will indicate the deletion.

Oversize materials (e.g., maps, drawings, charts) are reproduced by sectioning the original, beginning at the upper left-hand corner and contiming from left to right in equal sections with small overlaps. Each original is also photographed in one exposure and is included in reduced form at the back of the book.

Photographs included in the original manuscript have been reproduced xerographically in this copy. Higher quality $6^{\prime \prime} \times 9^{n}$ black and white photographic prints are available for any photographs or illustrations appearing in this copy for an additional charge. Contact UMI directly to order.

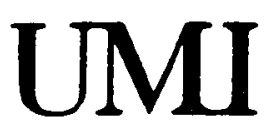

A Bell \& Howell information Company

300 North Zeeb Road. Ann Arbor. Ml 48106-1346 USA

313:761-4700 800:521-0600 



\title{
EFFECTS OF THE ORDER OF INSTRUCTIONAL ACTIVITIES ON THE ATTITUDES AND ACHIEVEMENT OF STUDENTS WORKING IN COOPERATIVE GROUPS
}

\author{
A Thesis \\ Presented to \\ The Faculty of the College of Education \\ San Jose State University \\ In Partial Fulfillment \\ of the Requirements for the Degree \\ Master of Arts
}

by

Christine Mack Campbell

May 1995 
UMI Number: 1374568

OMI Microform 1374568

Copyright 1995, by UMI Company. All rights reserved.

This microform edition is protected against unauthorized copying under Title 17, United States Code.

\section{UMI}

300 North zeeb Road

Ann Arbor, MI 48103 
APPROVED FOR THE COLLEGE OF EDUCATION
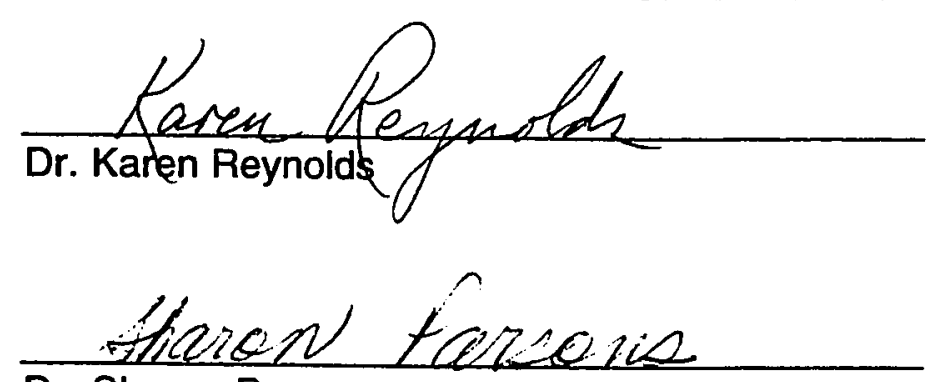

Dr. Sharon Parsons

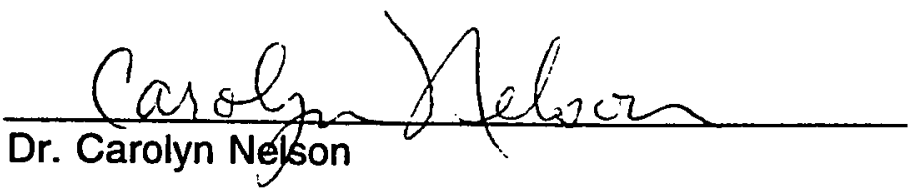

APPROVED FOR THE UNIVERSITY

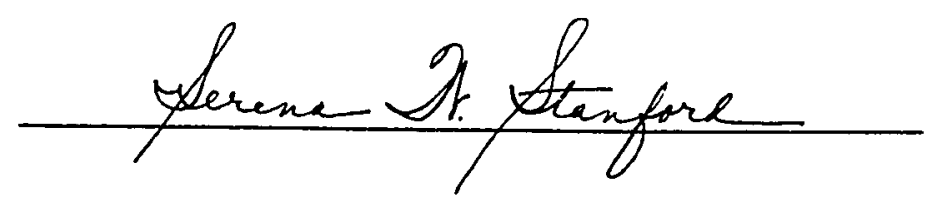


(C) 1995

Christine Mack Campbell

ALL RIGHTS RESERVED 


\section{ABSTRACT \\ Effects of the Order of Instructional Activities on the Attitudes and Achievement of Students Working in Cooperative Groups by Christine Mack Campbell}

This study explored whether the order of instructional activities, (1) hands-on experiments followed by a computer simulation or (2) computer simulation followed by hands-on experiments, made a difference on the achievement and attitudes of students working in cooperatively structured groups learning about simple machines.

Three classes, including 101 upper elementary students in the Cupertino Union School District completed a pretest, participated in six periods of science instruction (three computer-based and three hands-on), and then completed a posttest. Attitude and achievement data were analyzed using t-test and chisquare statistics.

Findings significant at the .05 level were: (1) students in the handson/computer-based condition had significantly more favorable attitudes toward using the computer following instruction; and (2) students in the computerbased/hands-on condition had significantly more favorable attitudes toward working with their group. No significant differences vere found between (1) treatment conditions on achievement, or (2) males and females on attitude or achievement. 


\section{Acknowledgments}

A warm thank you to my parents, Carl and Joan Mack, for their encouragement, support, and belief in higher education. An appreciative thank you to my husband, Nathan; my sister, Lynda Wootan; and all of my friends who listened and supported me while I was immersed in the thesis process. A sincere thank you to Dr. Karen Reynolds for her guidance and insight. A gigantic thank you to Sig Mejdal for the time he generously spent helping me make sense of the statistics. I dedicate this thesis to Mom and Dad for enabling me to pursue this goal. 


\section{CONTENTS}

Page

List of Tables

ix

Chapter

I Introduction 1

$\begin{array}{ll}\text { Problem Statement } & 2\end{array}$

$\begin{array}{ll}\text { Purpose Statement } & 4\end{array}$

Research Questions $\quad 4$

$\begin{array}{ll}\text { Hypotheses } & 5\end{array}$

$\begin{array}{ll}\text { Assumptions } & 6\end{array}$

$\begin{array}{ll}\text { Limitations } & 7\end{array}$

$\begin{array}{ll}\text { Operational Definitions } & 7\end{array}$

$\begin{array}{ll}\text { Statement of Significance } & 8\end{array}$

$\begin{array}{ll}\text { II. Review of the Literature } & 10\end{array}$

Hands-on Science, Computer-based, and Cooperative 10

Learning

$\begin{array}{ll}\text { Hands-on Science and Computer-based } & 11\end{array}$

$\begin{array}{ll}\text { Hands-on Science and Cooperative Learning } & 18\end{array}$ 
Computer-based and Cooperative Learning

Science

Hands-on Science

Computer-based

Cooperative Learning

III. Method

Introduction

Research Questions

Research Population

Description of Instruments

Hypotheses

Data Analysis

Introduction

Results Reported by Hypothesis 
V. Summary and Discussion 93

$\begin{array}{ll}\text { Overview of Study } & 93\end{array}$

Attitude Findings: Summary and Discussion 94

Achievement Findings: Summary and Discussion 100

Gender Findings: Summary and Discussion 101

$\begin{array}{ll}\text { Additional Findings: Summary and Discussion } & 102\end{array}$

$\begin{array}{ll}\text { Classroom Implications } & 104\end{array}$

$\begin{array}{ll}\text { Implications for Further Research } & 105\end{array}$

$\begin{array}{ll}\text { Conclusion } & 107\end{array}$

$\begin{array}{ll}\text { References } & 110\end{array}$

$\begin{array}{ll}\text { Appendix } & 123\end{array}$

A. Pretest: Pre-Questionnaire

B. Posttest: Post-Questionnaire 


\section{LIST OF TABLES}

Table

Page

1. Responses Reflecting Attitude Toward Hands-on and CAI

76

2. Responses Indicating Attitude Toward Cooperative

78 Learning Groups

3. Rating of Instructional Strategies as Perceived by Students to Help them Learn Content

81

4. Achievement Results 84

5. Preferences When Engaging in Hands-on Activities 87

6. Preferences When Engaging in Computer-based Activities 88

7. Summary of Results 99 


\section{CHAPTER I}

\section{INTRODUCTION}

Hands-on instruction, computer-assisted instruction, and cooperative learning are popular teaching approaches used in the elementary classroom. Studies of computer-assisted instruction (CAl) suggest a variety of significant achievement and affective/motivational gains through computer use (Kulik, Bangert, \& Williams, 1983; Perez \& White, 1985). CAl appears to be most effective when used as a supplement to other methods of instruction, rather than as the sole source of instruction (Crosby, 1983; Edwards, Norton, Taylor, Weiss, \& Dusseldorp, 1975; Kulik \& Bangert Drowns, 1983; Okey, 1985).

Very few studies have been conducted that investigated the potential of CAl in the teaching of concepts in science (Becker, 1984; Roblyer, Castine, \& King, 1988), although preliminary findings have shown highly positive effects of computer simulated experiences (CSE) on science achievement (Roblyer et al., 1988). Shaw and Okey (1985) suggest that students who have trouble mastering certain skills or science concepts may benefit from working with both computer simulations and hands-on activities, which reinforce learning.

Cooperatively structured learning has been shown to promote (1) higher achievement and productivity than competitive and individualistic learning situations (D.W. Johnson, Maruyama, R.T. Johnson, Nelson, \& Skon, 1981), (2) positive perception of support, help, and friendship from teachers and peers (D.W. Johnson \& R.T. Johnson, 1983), and (3) more interpersonal attraction 
among students who had been initially prejudiced against each other (Cooper, D.W. Johnson, R.T. Johnson, \& Wilderson, 1980).

Science, with its emphasis on experimenting and critical thinking, is believed to be an excellent place to start cooperative interaction among students and to teach the skills that will make them more effective in working with each other (R.T. Johnson \& D.W. Johnson, 1979). Evidence from two preliminary studies investigating the effects of integrating computer-assisted instruction and cooperative learning have shown that computer-assisted cooperative instruction promotes a greater quantity and quality of daily achievement in eighth graders, as well as more successful problem solving, more task-related student-student interaction, and a higher status for female students, than do computer-assisted competitive instruction and computerassisted individualistic instruction (D.W. Johnson, R.T. Johnson, \& Stanne, 1985a, 1985b). Even though the integration of computer-assisted instruction and cooperative learning has strong implications for improved achievement and attitudes of students, there is a paucity of research that addresses this approach in science.

\section{Problem Statement}

Today many students work individually, or in non-cooperatively formed groups on simulation programs at the computer. The findings of Johnson et al. (1985a, 1985b) indicate that working in non-cooperatively structured groups at the computer may result in a lower level of achievement, and more negative attitudes toward peers, than would working in cooperatively formed groups. 
Yager (1984) found that the attitudes of fourth to sixth grade students toward science declined as they got older. Yager (1986) found that students learned more science from hands-on experiences and interaction with one another than in isolated science classrooms of traditional schools.

Hider and Rice (1988) found that the integration of left hemispheric (textbook based) and right hemispheric (hands-on) strategies resulted in attitude gains three times greater than either strategy used in isolation. Achievement gains were the greatest in the textbook (left hemispheric) group. The hands-on (right hemispheric) group showed the smallest gains in achievement.

Research supports the integration of strategies when teaching science in order to meet the different learning styles of students and to promote academic and attitude gains (Hider \& Rice, 1988; Showater, 1984). Gardner, Simmons, and Simpson (1992) found that the combination of hands-on activities and CAI resulted in significantly higher gains in knowledge and attitudes as compared to the hands-on only group. Both hands-on and the combination of CAl with hands-on led to increased understanding and more positive attitudes than the text-based instruction (Gardner et al., 1992). Further research is required to identify the usefulness of integrating computer-simulated experiences and hands-on experiments on learning outcomes. Access to a class set of hands-on science materials and computers is limited, suggesting a rotational management system. It is not known, however, whether the order in which instructional activities (hands-on and computer-based) are carried out makes a difference on the achievement and attitudes of students who are working in cooperatively structured groups. 


\section{Purpose Statement}

The purpose of this study was to determine whether the order of two instructional activities, (1) hands-on experiments followed by a computer simulation or (2) a computer simulation followed by hands-on experiments, made a difference on the achievement and attitudes of students working in cooperatively structured groups. Subjects' perceptions of the hands-on activities, the computer program that they used, and working in cooperatively structured groups were investigated. Student attitudes were measured using Likert-type scales and open-ended questions. Student achievement was measured using pictorial multiple choice questions and open-ended questions.

\section{Research Questions}

The following are research questions addressed in this study: 1. Does the order in which two contrasting instructional activities are experienced affect the attitudes of students toward hands-on and computerbased instruction?

2. Does the order in which two contrasting instructional activities are experienced affect student attitudes toward working in groups?

3. Does the order in which two contrasting instructional activities are experienced affect the perceptions of students toward the hands-on, computerbased, and cooperative learning instructional settings?

4. Does the order in which two contrasting instructional activities are experienced affect achievement? 
5. Is there a relationship between gender and student attitudes?

6 . Is there a relationship between gender and achievement?

\section{Hypotheses}

The six pairs of hypotheses addressed in this study are listed below.

A. Hypothesis: The order in which two contrasting instructional activities are experienced results in attitude differences toward hands-on and computerbased instruction that are significant at the .05 level.

Null Hypothesis: The order in which two contrasting instructional activities are experienced does not result in attitude differences toward handson and computer-based instruction that are significant at the .05 level.

B. Hypothesis: The order in which two contrasting instructional activities are experienced affects student attitudes toward cooperative learning groups at the .05 level of significance.

Null Hypothesis: The order in which two contrastirig instructional activities are experienced does not affect student attitudes toward cooperative learning groups at the .05 level of significance.

C. Hypothesis: Student perceptions of how the F.O.S.S.: Levers and Pulleys experiments, Miner's Cave computer program, and their cooperative learning group helped them learn the science content are influenced by the order in which they experienced the two contrasting instructional activities.

Null Hypothesis: Student perceptions of how the F.O.S.S.: Levers and Pulleys experiments, Miner's Cave computer program, and their cooperative 
learning group helped them learn the science content are not influenced by the order in which they experienced the two contrasting instructional activities.

D. Hypothesis: The order in which two contrasting instructional activities are experienced results in achievement differences that are significant at the .05 level.

Null Hypothesis: The order in which two contrasting instructional activities are experienced does not result in achievement differences that are significant at the .05 level.

E. Hypothesis: Gender affects the attitudes of students toward the instructional setting at the .05 level of significance.

Null Hypothesis: Gender does not affect the attitudes of students toward the instructional setting at the .05 level of significance.

F. Hypothesis: Gender affects the achievement of students at the .05 level of significance.

Null Hypothesis: Gender does not affect the achievement of students at the .05 level of significance.

\section{Assumptions}

During the course of the study, the following was assumed:

1. The pre- and posttests were valid measures of achievement and attitudes.

2. Students were able to read all questions posed on the assessments. If not, students would ask for clarification.

3. Instruction given in both treatment conditions was uniform. 


\section{Limitations}

1. The sample is limited to 96 sixth grade students and five fifth grade students at West Valley Elementary School in the Cupertino Union School District, Cupertino, California.

2. Interviews were not conducted to clarify student responses on the assessments.

3. Student disinterest in a research project might affect quality of response.

4. The posttest was completed two weeks prior to summer vacation, a factor that might affect the quality of responses on the posttest.

\section{Operational Definitions}

For the purposes of the study, key terms are defined as follows:

1. Computer-Assisted Instruction (CAl): This study defines computer-assisted instruction as the interaction between a computer system and one or more students for the purpose of promoting learning in subjects such as math, language arts, science, and problem solving skills (Brown, 1986).

2. Cooperative Learning. A learning situation in which all members of a group work together to solve a problem or complete a task. In a cooperative learning situation, when one student achieves his or her goal, all other members of his or her group achieve their goals (Deutsch, 1962; D.W. Johnson \& R.T. Johnson, 1975). Members of the cooperative learning group discuss the material with each other, help one another understand it, and encourage one another to work hard (R.T. Johnson, D.W. Johnson, \& Anderson, 1978; Male, 1988). 
3. Hands-on Science: Hands-on is sometimes referred to as the inquiry-based or process approach to teaching and learning about science. Children engaged in activity-oriented science can be seen manipulating materials, observing, inferring, collecting data, classifying, predicting, experimenting, and solving problems (Jaus, 1977). The hands-on method emphasizes experiencing science as a process and positive science experiences.

4. Problem Solving. The ability to use thinking to combine principles or concepts in order to obtain new solutions (Zintz \& Maggart, 1984).

5. Simulation Programs: Simulation programs enable students to experiment with models of real world situations by making decisions and controlling environmental variables. It is believed that the skills developed when using simulation programs are transferable to real world problems and enhance problem solving abilities (Norton \& Resta, 1986).

\section{Statement of Significance}

Computer-assisted instruction, hands-on science instruction, and cooperative learning have been shown to be effective teaching approaches when used by themselves. All have been shown to have positive effects on achievement (Bredderman, 1983; Johnson et al., 1981; Kulik, Bangert, \& Williams, 1983; Perez \& White, 1985; Shymansky, Kyle, \& Alport, 1983); computer-assisted instruction has been shown to be highly motivational (Kulik et al., 1983; Perez \& White, 1985); hands-on science instruction has been shown to promote achievement and attitude gains (Jaus, 1977; Kyle, Bonnstetter, Gadsden, Jr., \& Shymansky, 1988; Shymansky, Hedges, 
Woodworth, \& Berg, 1986); and cooperative learning has been linked to positive perceptions of group members (D.W. Johnson \& R.T. Johnson, 1983) and more interpersonal attraction among children previously prejudiced against one another (Cooper et al., 1980).

Johnson et al. (1985a, 1985b) provided preliminary evidence supporting the integration of computer-assisted instruction and cooperative learning to improve daily achievement, problem solving ability, task-related interaction patterns, and the status of female students. The findings of Johnson et al. (1985a, 1985b) are encouraging and merit further investigation. This is one of the many studies needed to further investigate the effects of integrating computer-assisted instruction and cooperative learning in the science curriculum. Specifically, this study attempts to determine whether the order in which instructional strategies are experienced, i.e.,hands-on experiments followed by computer-assisted instruction or computer-assisted instruction followed by hands-on experiments, makes a difference on the achievement and attitudes of students working in cooperatively structured groups. 


\section{CHAPTER ||}

\section{REVIEW OF LITERATURE}

The purpose of this chapter is to review studies that investigated the effects of (1) hands-on science instruction, (2) computer-based instruction, and (3) cooperative learning approaches on the attitudes and achievement of elementary, middle school, and college students. A study that included all three instructional approaches is reported first, followed by studies that included two of the instructional approaches, and studies that included one of the instructional approaches third. This review provides background from which to recognize limitations and discuss the results of this research study.

\section{Hands-on Science, Computer-based, and Cooperative Learning}

Dalton (1990) suggests that many teachers are reluctant to use cooperative learning methods because the potential for off-task behavior could increase. However, since computer-based methods provide precise pacing control, which enables students to increase time-on-task, computers may provide an effective means for implementing cooperative learning (Cox \& Berger, 1985; D.W. Johnson \& R.T. Johnson, 1983; Simpson, 1986; Webb, 1985b).

Dalton (1990) investigated the effects of learner control versus lesson paced instruction for 49 pairs of sixth grade students during an interactive video 
science lesson. Students in the learner control treatment who were allowed to proceed through the lesson at their own pace significantly outscored students in the control/lesson paced treatment where frames were presented at a predetermined rate based on average reading speed. Same sex pairs were significantly more efficient than mixed pairs. Students in the lesson paced pairs spent more time on task and less time socializing. Males responded most favorably to the learner control treatment, and females preferred the lesson paced treatment. Females had significantly less positive attitudes toward science. Male/male teams consistently competed for control of the keyboard, were reluctant to take turns, and had difficulty cooperating. Male/male partnerships that got along began competing with other pairs.

\section{Hands-on Science and Computer-based}

\section{Hands-on and Computer-Assisted Instruction}

The potential of CAl in the teaching and learning of science concepts has been researched to a small degree (Becker, 1984; Roblyer et al., 1988).

Preliminary findings have shown highly positive effects of computer simulated experiences (CSE) on achievement (Aielio \& Wolfe, 1980; Okey, 1985; Roblyer et al., 1988; Willitt, Yamashita, \& Anderson, 1983) when compared to other science teaching methods. Research in the affective domain indicates that student attitudes and interests seem to be positive toward using microcomputers in science education (Helgesson, 1988). 
Gardner, Simmons, and Simpson (1992) investigated the effects of CAI and hands-on activities on the attitudes and acquisition of knowledge of weather concepts. Five third grade classes were randomly assigned to one of three treatments: (1) hands-on activity emphasis, (2) same hands-on activities along with the Weatherschool program, or (3) text-based learning emphasis. Results indicated that the hands-on activities appeared to increase knowledge of and attitudes toward science. The combination of hands-on activities and CAI resulted in significantly higher gains in knowledge and attitudes as compared to the hands-on only group. Gardner et al. (1992) noted that hands-on only and hands-on plus CAl led to increased understanding and more positive attitudes than text-based instruction.

\section{Hands-on and Microcomputer Simulations}

Cavin, Cavin, and Lagowskil (1981) investigated the effect of CAI on college students' attitudes toward the computer and chemistry, and whether or not male and female students demonstrated different attitudes. Results indicated the attitudes of students in the CAI group toward the computer improved, but those of the control group did not. Attitudes toward chemistry did not improve. Cavin et al. (1981) attributed the attitude increase to the females in the CAl group. It was suggested that the interactive, non-threatening aspects of the computer may have contributed to this reaction among the women.

Shaw and Okey (1985) compared the effects of alternative ways of using microcomputer simulations on the achievement and attitudes toward computers and science instruction of sixth and seventh grade students. Students from nine 
classes at an intermediate school were randomly assigned to one of the following treatments: (1) only microcomputer simulations, (2) only laboratory activities, (3) a combination of laboratory and simulation activities, and (4) conventional instruction.

Results indicated that the three treatment groups performed significantly higher on the achievement measure than the comparison/conventional group. No significant effects of instructional treatments were found on attitudes toward computers and science instruction. It appears that non-conventional modes of instruction in science have a positive effect on achievement. The researchers note that students had no opportunity to interact with the computer simulations on their own which may have inhibited learning. In addition, students having trouble mastering certain skills or science concepts may benefit from working with both computer simulations and hands-on activities which reinforce learning. Researchers explain that this study's lack of support for the previous findings that computer simulations when compared to conventional instruction have shown positive effects on attitudes, may be due to the short duration of the study (two weeks) and the fact that students in this study were accustomed to using computers.

Choi and Gennaro (1987) compared the effectiveness of microcomputersimulated experiences with instruction involving hands-on laboratory experiences for teaching the concept of volume displacement. Gender differences and degree of retention were also investigated. Sixty-three male and 65 female eighth grade students participated in the study. Boys were randomly assigned to the microcomputer-simulation group (experimental) and 
the hands-on laboratory group (control). Girls were then randomly assigned to one of the two groups.

Six specific concepts were taught to each treatment group. The experimental group used a series of five simulated experiences on the microcomputer. The control group used five parallel hands-on laboratory experiences. Since the content was parallel, control and experimental groups discussed concepts investigated together.

Posttest scores revealed no significant differences between the performance of students in the simulation group or hands-on group in the learning of the concept of volume displacement. However, males scored significantly higher than females on the posttest. Analysis of the retention test scores indicated that there were no significant differences on retention levels when retention test scores of the simulation and hands-on groups were compared. Males did score consistently higher on the retention test in both treatment conditions.

Choi and Gennaro (1987) point out that the achievement results of this study support the findings of Jones (1972) and Cavin and Lagowskil (1978) that computer-simulated experiments were as effective as hands-on experiences. Also supported are the findings of Edwards et al. (1975), Thomas (1979), and Kulik et al. (1981) that retention levels are comparable for CAI and non-CAI courses. Findings of this study, in addition to previous data (Cavin \& Lagowskil, 1978; Jones, 1972; Lunetta \& Blick, 1974) imply that a computer-simulated experiment can be used in place of a hands-on experiment with equal performance expected when certain topics are covered in secondary school 
science. An additional implication is that CSE may result in equal learning in one fourth the time of hands-on experimentation. Researchers suggested that studies be conducted to identify the usefulness of combining CSE and handson experiences on learning outcomes.

DeClercq and Gennaro (1987) investigated the effectiveness of supplementing science instruction with an interactive computer simulation. The study included ninth grade students being taught the volume displacement concept. Both control and experimental groups completed regular text materials, demonstrations, and experiments on volume displacement. The randomly assigned experimental group then received 10-20 minutes of additional instruction on the concept using a computer simulation. The experimental group scored significantly higher than the control group on the posttest administered 55 days after instruction. This finding indicates that supplemental computer simulations may have positive effects on learning science concepts.

Rivers and Vockell (1988) summarized the results of three related studies conducted from 1981 to 1983 with high school biology students representing various socio-economic classes and ethnic groups. Full descriptions of each study can be found in Vockell and Rivers (1984a; 1984b). The purpose of these studies was to determine the effectiveness of simulations in enhancing problem solving abilities. Biology classes were first divided into either treatment classes or control classes. The treatment classes were then divided into guided and non-guided simulation groupings. 
Students in the treatment classes used the computers as an integrated part of the laboratory experience in their science course. Small groups of three to five students prepared for the simulations by studying the laboratory guides and determining what variables to manipulate in the simulation. Next, they would conduct their pre-planned experiments using the computer simulations. Last, they analyzed the data and drew conclusions in small groups away from the computers. Treatment classes used the simulations to help in dealing with the topics. Control classes were taught equivalent topics using textbook, lecture, and traditional laboratory experiences.

Results of the year long studies indicated that the computerized simulations that were used enabled students to master the objectives of a biology course as effectively as more traditional methods. There were no instances where control students achieved more than the students using the computer simulations. Students using computer simulations seemed to transfer or generalize problem solving learned in one unit, to subsequent units. The students that used guided simulations appeared to develop general problem solving skills more effectively than students using the unguided version. Rivers and Vockell (1987) suggest that problem solving skills may be enhanced through the use of integrated simulations, because students working at the computers receive more opportunities for active, reinforced practice.

Simulations and games have been said to allow students to examine models of the real worid under controlled conditions, and to study variables that might otherwise be inaccessible (Tamir, 1985/86). This capability of the microcomputer to provide models of scientific phenomena or systems has 
significant potential for science teaching. Studies investigating the effectiveness of simulation software as a replacement for traditional instruction have had favorable results (Choi \& Gennaro, 1987; Roblyer et al., 1988; Shaw \& Okey, 1985). The positive effects of supplementing science instruction with simulation software have been reported by many researchers (Choi \& Gennaro, 1987; DeClercq \& Gennaro, 1987; Rivers \& Vockell, 1987; Roblyer et al., 1988; Shaw \& Okey, 1985). CAl has been reported to have positive effects on student attitudes (Gardner et al., 1992; Roblyer et al., 1988). Shaw and Okey (1985) found that the attitudes of students of the three treatment groups (simulation only, hands-on only, and combination) were no different from those of the control group. The short duration of their study was suggested as a reason that these findings may not be representative. Further research investigating the effect of CSE on attitudes needs to be conducted.

\section{Need for Further Research Involving Computer Simulations}

The research studies investigating the effectiveness of drill-and-practice and tutorial-based CAl programs far out number those investigating the effectiveness of problem solving and simulation software. The review of the literature suggests that more studies investigating the effects of problem solving and simulation CAI programs on student learning and thinking at different age and ability levels are required to provide a clear picture of effects on learning. It is possible that higher-achieving students, when challenged, would excel more than they would carrying out lower level tasks. Beasley (1985) and Walkington and Babcock (1984) both recommend that computers and CAl be used with 
gifted or high-achieving students. Not only can CAI be used to introduce a new content area, but through the use of a simulation program, CAI can provide the student with an opportunity to investigate the effect of variables on a real world situation (Beasley, 1985). Another possible strength of simulation programs indicated in a review of CAI research by Clark (1984) is in the area of transfer. Clark (1984) points out that learning achieved through the use of drill-andpractice does not transfer to novel problems. However, learning from simulation programs where the learner has more control does seem to transfer to new situations. Despite the educational potential of using simulations, research aimed at elementary school students has been minimal. More research into these areas must be conducted in order to establish whether or not these initial findings are prevalent.

\section{Hands-on Science and Cooperative Learning}

\section{Rationale for Combining Science and Cooperative Learning}

Science, because of the emphasis on experimenting and critical thinking, is suggested to be an excellent place to start cooperative interaction and teach the skills that will make students more effective in working with each other (R.T. Johnson \& D.W. Johnson, 1979). Having students work together during science is cost effective (R.T. Johnson \& D.W. Johnson, 1979; Jones, 1985) and if students are taught to work cooperatively with each other, the following learning outcomes can be achieved: (1) achievement in science, (2) divergent thinking and effective problem solving, (3) positive attitudes toward science, the teacher, 
and each other; (4) intrinsic motivation, (5) positive self-esteem, (6) effective social skills, and (7) effective mainstreaming of handicapped students (R.T. Johnson \& D.W. Johnson, 1979).

Cooperative learning methods that emphasize (1) interactions, (2) group rewards, and (3) individual accountability have been found to foster achievement gains. Attitude and self-esteem gains have resulted when cooperative learning methods emphasize interactions and individual accountability (Slavin, 1987).

Yager (1986) reported that the emphasis on mastering a textbook during the course of a year resulted in decreased student interest and lack of concept learning. Yager (1986) also found that students learned more science from hands-on experiences and interaction with one another than in isolated science classrooms of traditional schools.

\section{Computer-based and Cooperative Learning}

Computer-assisted instruction and cooperative learning appear to be worthwhile, educationally sound teaching methods. In the early eighties, researchers aware of the effects of CAl and cooperative learning as separate strategies, began to investigate the effects of CAl and cooperative learning used together.

Webb (1984) examined the types of interaction that occurred among 35 junior high school students who worked together in small groups (two or three 
students per group) at the computer. Group members were told to work together, help those who were having trouble, and ask other group members for help. Each group had access to one computer, corrected their own errors, and formulated a group plan for learning computer programming using the worksheets and other materials provided to them. Findings indicated that small groups may be a workable setting for learning computer programming. Verbal interaction among group members appeared to help in learning basic commands and the proper way to enter commands, but they did not appear to influence learning how to interpret and create graphics programs. Webb (1984) suggested that further research be done to investigate whether or not different student characteristics among groups foster different computing outcomes.

R.T. Johnson, D.W. Johnson, and Stanne (1985) examined the effects of cooperative, competitive, and individualistic goal structures at the computer on the achievement and attitudes of 71 eighth-grade students. The researchers suggested that the method of assigning one student per computer may inhibit social interaction and may not be the most effective use of the computer. It is possible that working in pairs or groups at the computer may foster more learning, as well as improved attitudes. Students in each condition participated in a ten-day instructional unit that combined a computer simulation with written materials on the basics of map reading and navigation.

Findings indicated that computer-assisted cooperative learning promoted higher achievement, greater mastery of factual information, greater ability to apply one's factual knowledge, and greater ability to use factual information to 
answer problem solving questions. Cooperation also appeared to create more motivation to accomplish learning goals than either the competitive or individualistic structures. In addition, students who cooperated had a greater understanding of the concepts, retained more, and worked faster and more accurately than students in the other conditions.

The way students interacted with one another was also shown to be influenced by the goal structure. For example, very few comments took place in the competitive and individualistic structures. Of the comments that took place, some were task related and others were either directed to the teacher or were unrelated to the task. In the cooperative situation, students regularly shared task-related information with one another and initiated almost no interaction with the teacher. The researchers pointed out that: "the type of interaction which occurred in the cooperative situation (learning oriented) has been linked to the use of higher level reasoning strategies, conceptıal understanding, and longterm retention of information being learned" (R.T. Johnson, D.W. Johnson, \& Stanne, 1985, p. 675).

Findings from this study indicated possible sex differences among the three conditions. Boys scored higher on recognition and problem solving on the final examination, were more competitive, perceived more academic support from teachers, and perceived the computer to be more of a male domain. Girls who had worked in the cooperative condition liked working with computers more than the boys did. In the competitive condition, the opposite was true. Girls in the competitive condition tended to do worse than those in the other 
conditions. Both girls and boys achieved more when involved in computerassisted cooperative instruction than in the other conditions. Therefore, CAI and cooperative learning appear to be a productive combination of instructional strategies.

R.T. Johnson, D.W. Johnson, and Stanne (1986) replicated their 1985 study in an effort to further investigate the relative effectiveness of computerassisted cooperative, competitive, and individualistically structured learning. Students in the cooperative condition demonstrated a variety of achievement gains: (1) higher daily achievement, (2) greater recognition of factual information studied and the ability to apply facts, (3) more success in a complex problem solving task, and (4) greater success in operating a computer program. Students in the cooperative and competitive conditions scored higher on the achievement test than those students in the individualistic condition. Interactions in the cooperative condition were more task-related, and less social than the interactions in the other conditions. Students in the cooperative condition also had more favorable perceptions of their group members.

The findings of R.T. Johnson, D.W. Johnson, and Stanne $(1985,1986)$ provide initial support for the use of computer-assisted cooperative instruction. These studies indicate (1) higher achievement, (2) more on-task interaction, (3) an increase in problem solving capabilities, and (4) more positive perceptions of peers among students in cooperatively structured groups as compared to students in competitive and individualistically structured settings. 
Light, Foot, Colbourn, and McClelland (1987) conducted two studies in which they investigated student interactions at the computer. In the first study 60 eight-year-old students representing equal numbers of boys and girls were pretested and randomly assigned to three conditions: (1) individual, (2) paired unstructured interaction, or (3) paired structured interaction. The difference between the structured and unstructured situations was the fact that groups of keys at opposite ends of the keyboard had to be pressed at the same time to be accepted in the structured setting. The students participating in the structured interaction condition scored higher on the individual post-test than did members of the other conditions. It appeared that the "dual key" requirement enhanced the productivity of the paired experience.

The researchers pointed out that the pairing of students was random and did not take into account the children's established social relationships in the first study. Therefore, in the second study, students selected three students with whom they enjoyed working. The researchers used the students' input to form eight groups of three eleven-year-olds. Four of the groups included students who had included the other two in their selection. The remaining four did not include members who had selected one another, and were balanced according to ability levels. The experiment was begun a week after the selection had taken place, and the researchers saw no indication that the students found a connection between the two activities. In this study students did not complete pre- or posttests. During the final session students completed a computer-based 
questionnaire. The researchers also used video cameras and their own observations to gather data on students' behavior.

Students who had selected one another demonstrated more positive and supportive types of interaction, although the differences were not statistically significant. These students also required fewer teacher mediations and made significantly fewer careless minor errors. The girls tended to show more positive attitudes toward the collaborative work at the computer than did the boys.

Hooper and Hannafin (1988) compared the achievement of low and high ability eighth grade students working in cooperative groups on a fictitious rulebased number system program at the computer. The 40 students representing equal numbers of males and females from high (pre-algebra) and low ability (general math) levels were assigned to one of three cooperative groupings: (1) homogenous high, (2) homogenous low, and (3) heterogeneous. Individual cooperative learning groups had four members each.

Posttest results indicated that the low ability students in the heterogeneous group experienced a $51 \%$ gain in learning over the homogenous low ability group. Conversely, the high ability students in the heterogeneous group showed a $9 \%$ decrease in achievement compared to the high ability students in the homogenous high group. Because the gain was so great for the low ability students in the heterogeneous group and the loss was so minimal for the high ability students in the same group, the researchers suggested that cooperative learning posed little risk to more able tutors. Although lower achieving students 
did show growth in achievement, gains were much greater in the areas of factual and application skills rather than in higher level skills such as problem solving.

Hooper and Hannafin (1988) suggested that cooperatively structured learning fosters (1) academic achievement, (2) concern for other students' well being, and (3) enhanced self-esteem of low-ability students. The researchers also pointed out that having used individual incentives rather than group incentives may have limited the amount of cooperation among group members. If the high ability students knew that their reward was dependent on the scores of their low ability group members, they may have offered more help. Likewise, the low ability students may have felt more comfortable asking for help.

\section{Science}

\section{Student Characteristics and Science Performance}

Fleming and Malone (1983) conducted a meta-analysis to investigate the relationship of student characteristics to student performance in science. Results of studies conducted from 1960 to 1981 that involved students in kindergarten through twelfth grade were analyzed. Findings revealed that general ability, language ability, and mathematical ability had the strongest positive relationship to performance on science achievement, cognitive, and science attitude measures across all grade levels and science content areas. Overall, science achievement and cognitive measures demonstrated stronger relationships with student characteristics than did attitude measures. 
Gender was shown to have the weakest relationship to science achievement, science attitudes, and cognitive measures. In general, males scored slightly higher than females. At the middle school level, males were found to perform better than females on science achievement and cognitive measures. Females at the middle school were found to have more positive attitudes than males.

\section{Influences on Attitudes and/or Achievement in Science}

Simpson and Oliver (1985) included students from grades six through ten in a study investigating attitudes toward science and motivation to achieve in science. Twelve schools from one district were randomly selected to participate. A total of 178 science classes, 57 teachers, and 4000 students were included. Attitude and achievement measures were completed at the beginning, middle, and the end of the year.

The most significant findings from this year long study included: (1) attitudes toward science declined steadily from grade six to grade eight; (2) males indicated significantly more favorable attitudes toward science than females; (3) attitudes toward science of all students declined drastically from the beginning of the year to the middle of the year, and gradually from the middle of the year to the end of the year; (4) achievement scores declined steadily from grade six through grade ten; and (5) female students were significantly more motivated to achieve in science than males.

Simpson and Oliver (1990) reported the findings of a ten year study that examined the effects of home, school, and individual influences on adolescent 
students' attitudes toward science and their achievement in science. Twelve schools, 78 teachers, 178 science classes, and 4500 students were included in the study. Four elementary, junior high, and high schools participated. Attitude and achievement measures were completed at the beginning, middle, and end of the 1980-1981 school year. Semester grades, teacher questionnaires, and evaluations of the participating teachers by the science supervisor were collected.

Curriculum, class climate, friends, best friend, teacher, and physical environment consistently showed a high correlation with student attitudes toward science. A strong relationship was also found between a student's science self concept and attitude toward science. However, this relationship was not as strong as the six school variables listed above. Males were found to have significantly more positive attitudes toward science and achieved at higher levels than females. Females were found to be more motivated to achieve in science. Students who were classified as "middle ability" demonstrated a more rapid decline in their attitude toward science than the advanced or basic groups.

The follow-up study was conducted during the 1985-1986 school year. Researchers investigated whether or not earlier measures of attitude and achievement in science could be used to predict later achievement and participation in science. Results indicated the combination of attitude, motivation toward science, and achievement in initial science classes served as an important influence during high school. If a student was not supported at home, received little or no science in elementary school, and did not have positive 
science experiences at the junior high; data suggested that the student would avoid science in high school.

Simpson and Oliver (1990) gave the following suggestions for further research: (1) science education needs to be addressed at the elementary and junior high level; (2) more attention needs to be given to science in the elementary schools; and (3) science classes being taught in the junior high schools need to be evaluated to determine their effectiveness with a large student population.

\section{Hands-on Science}

A popular instructional method in science is the hands-on approach which is sometimes referred to as the inquiry-based or process approach to teaching and learning about science. Jaus (1977) stated: "Children engaged in activity-oriented science can be seen manipulating materials, observing, inferring, collecting data, classifying, predicting, experimenting, solving problems, etc. In essence, they are doing science" (p. 26). This method emphasizes experiencing science as a process and positive science experiences.

\section{Inquiry-based Programs Developed in the 1960's and 1970's}

The Elementary Science Study (ESS), Science Curriculum Improvement Study (SCIS), and Science-A Process Approach (SAPA) programs, developed in the sixties and seventies; incorporated hands-on, activity-based strategies. Effectiveness of the ESS, SCIS, and SAPA programs over traditional methods 
has been the focus of numerous research studies and meta-analyses. Shymansky (1989) reported that approximately 60 studies comparing the performance of students in one of these programs to students in more traditional programs have been conducted.

Shymansky, Kyle, and Alport (1983) used meta-analysis techniques to analyze 105 studies of the effects of innovative science curriculum and strategies at the elementary and secondary level. Thirty-four of these studies compared the effects of ESS, SCIS, and SAPA on student performance with the effects of traditional, textbook-based classrooms. Performance areas that were compared included: achievement, attitudes, process skills, related skills, analytic skills, and Piagetian tasks. The overall effect of ESS, SCIS, and SAPA programs on all performance areas measured were found to be positive. The average student who participated in the activity-based programs gained twelve percentile points. Twenty studies compared student achievement in new science curricula (ESS, SCIS, and SAPA) with achievement in traditional programs. Students participating in the three new programs outscored the students in the traditional classroom by up to 34 percentile points.

Twenty-one studies compared attitudes toward the new science programs with attitudes toward the traditional program. The attitude variable was addressed in three ways: (1) attitude toward the new course, (2) attitude toward science, and (3) attitude toward self. Student attitudes in each of these areas were more positive toward the new programs than toward the traditional setting. Differences ranged from three to 20 percentile points. 
Process skill development (observing, inferring, interpreting data, hypothesizing, and graphing) was analyzed in 13 studies. ESS, SCIS, and SAPA students scored at least 18 percentile points higher than students in the traditional program. Basic skills (reading, arithmetic computation, and communication) were analyzed in 31 studies. SCIS students scored eight percentile points higher, and SAPA students scored four percentile points higher than students in the traditional setting. Research data for ESS students on this variable were not found. The researchers found that students involved in the three process-approach science programs had high scores on standardized tests of general science achievement, process skills, analytic skills, language arts, and mathematics (Shymansky et al., 1983).

Bredderman (1983) analyzed the results of 57 controlled studies on the effectiveness of ESS, SCIS, and SAPA. Twenty-eight of these studies had also been included in the analysis by Shymansky et al. (1983). Outcome areas addressed were science process skills, science content, affective outcomes, creativity, intelligence, language, and mathematics. The overall effect of ESS, SCIS, and SAPA programs on all outcome areas combined were found to be positive. The average student who participated in the activity-based programs gained 14 percentile points. The effects of ESS, SCIS, and SAPA on science process knowledge, intelligence, and creativity were the highest of all outcomes analyzed.

Affective outcomes were drawn from 15 studies. Bredderman (1983) notes that although the effect size was small, it is consistent with findings comparing effects of other innovative methods on affective outcomes (Kulik, 
Kulik, \& Cohen, 1980; Peterson \& Janicki, 1979; Shymansky et al., 1983;

Weinstein, Boulanger, \& Walberg, 1982). Scores on standardized achievement tests indicate that activity-based programs compared to traditional programs do not affect science content achievement in a negative way. Activity-based programs could possibly result in slightly higher scores when averaged across all student populations.

The similar effect sizes calculated by Shymansky et al. (1983) and Bredderman (1983), in independent meta-analyses, indicate the positive effects of hands-on, process-approach strategies for teaching science compared to traditional methods. Gains were achieved in a wide range of performance areas/outcomes and at various grade levels when students participated in ESS, SCIS, and SAPA rather than in traditionally structured settings.

Shymansky, Hedges, Woodworth, and Berg (1986) reanalyzed the original data of Shymansky et al. (1983). Performance areas that were compared included achievement, attitudes, process skills, related skills, and analytic skills. The average student who participated in the activity-based programs gained nine percentile points as calculated in the reanalysis, compared to the 12 point gain calculated in the original meta-analysis. Process skills of the ESS, SCIS, and SAPA students were found to be 19 percentile points higher than those in the traditional instructional setting. Student attitudes or perceptions of ESS, SCIS, and SAPA programs were 17 percentile points higher than the attitudes/perceptions of students toward the traditional strategies. 
The reanalysis of Shymansky et al. (1986) provided additional information relating to the effects of ESS, SCIS, and SAPA independent of each other. No one program was successful at improving student performance in every area analyzed. ESS and SCIS resulted in significant gains in achievement, process skills, perceptions, and analytic skills. Information on the effects of activity-based science compared to traditional science instruction on certain subgroups of students was reported. Rural and urban classroom students, as well as boys and girls from medium and high socio-economic backgrounds appeared to perform significantly better than comparable students in non-traditional science classrooms.

Students involved in ESS, SCIS, or SAPA performed significantly better in three of the five performance areas on standardized tests, and significantly lower in one performance area (related skills) than those students using traditional textbased strategies. It should be noted that the studies used in the meta-analyses of ESS, SCIS, and SAPA did not include modern textbook series developed more recently; a variable that may have some effect (Kyle, Bonnstetter, \& Gadsden, 1988).

The positive effects of ESS, SCIS, and SAPA compared to traditional science teaching strategies have been investigated and analyzed. Consistent findings include: (1) gains in science content achievement, (2) improved math and language skills,(3) more positive attitudes, (4) increased science process skills, and (5) no negative effect on standardized test scores. 


\section{Effects of Hands-on Science on Attitudes}

Jaus (1977) found that activity-oriented science instruction significantly improved students' attitudes toward science and school. The study was conducted at a lower socio-economic school and involved 154 second, third, and fourth graders. One teacher was randomly selected at each grade level to participate in ten hours of training on teaching activity-oriented science. Following the training, the three teachers implemented activity-oriented science in their classrooms. Textbook-based instruction continued in the other three classrooms.

Activity-oriented science students gained at least ten points on the science attitude questionnaire. Textbook-based students showed no significant gain in attitude toward science. Gains in attitude toward school were significant for the activity-oriented classes. Jaus (1977) pointed out that uncontrolled classroom variables may have contributed to the attitude gains in the activityoriented classes. Data gathered on the pretest indicated that children's attitudes toward science decreased as they progressed through the grade levels, and children's attitudes toward school decreased significantly as they got older.

Kyle et al. (1988) analyzed student and teacher attitudes toward science in process-approach classes compared to traditional science classes. The Science Curriculum Improvement Study (SCIIS) was introduced into six of the 35 elementary schools during the 1983-1984 school year. Comparing SCIIS student and teacher attitudes toward science to those of students and teachers in non-SCIIS classes was the major goal for 1983-1984. The possibility of gender differences among student attitudes toward science was examined, and 
the attitudes of SCIIS teachers who had received science inservice education were compared to those of the non-SCIIS teachers.

Results gathered from questionnaires substantiated the findings of earlier research, that students had a preference for inquiry-oriented, process-approach science. Over 50 percent of the first year SCIIS students identified science as their first or second favorite subject, compared to 17 percent of non-SCIIS students. Classroom observation revealed that students in SCIIS classes were more actively engaged with the scientific process than non-SCIIS students. SCIIS students spent 82 percent of their class time working with manipulatives compared to non-SCIIS students who spent 32 percent of their class time working with manipulatives. Over 75 percent of SCIIS students found science to be fun, exciting, and interesting, whereas over 50 percent of non-SCIIS students found science to be boring.

The only significant gender finding among SCIIS students related to the "kind" of science males and females liked best. Both males and females liked life science equally well. However, females seemed to prefer physical science and males seemed to prefer earth science. In non-SCIIS classes, a significantly higher percentage of males identified science as either their favorite or second favorite subject. A significantly greater number of females identified science as their least favorite subject. Females in the non-SCIIS classes were: (1) less likely to feel as though their teacher liked them to ask questions, (2) less likely to feel successful as a result of their science experience, and (3) less likely to find their study of science to be useful. The SCIIS classes appeared to enhance the attitudes of females toward science and their science classes. 
Students in their second year of SCIIS maintained exceptionally positive attitudes toward science and interest in science (Kyle, Bonnstetter, Gadsden, Jr., \& Shymansky, 1988). Data gathered through questionnaires and observations indicated the value of appropriate inservice education. The researchers noted that inservice training enabled teachers to become knowledgeable about content and to model questioning skills and integration strategies. SCIIS teachers reported that the nature of process-approach science allowed them to convey a positive and exciting image of science and scientists to their students. The thorough inservice program, ongoing assessment of teacher, student, and program needs, and favorable attitudes of SCIIS students and teachers toward science education as described by the researchers, are evidence that in a well-planned program, process-approach science is more effective than textbook-based science.

Dawes (1987) suggested that "methods of teaching science, such as the inquiry method, do not just happen but must be understood, planned, and developed by the teacher" (p. 20) and that a lack of teacher training may lead to science not being taught on a regular basis. The goals of Dawes (1987) in his dissertation practicum were: (1) for primary teachers to spend more time teaching science to young children, (2) for primary teachers to develop expertise in their ability to teach science, and (3) to develop positive attitudes of students toward the subject of science.

Responses to pre- and post-questionnaires revealed that 182 out of 210 first, second, and third grade students recorded an increase of at least two additional positive responses on the post-questionnaire. Teachers reported a 
commitment to increase time spent teaching science and that they had begun developing their expertise in teaching science. Observations verified that teachers were teaching and developing high interest, hands-on science instruction.

Vorsino (1990) designed a practicum to improve science instruction for first graders by developing curriculum materials. Goals were to increase instructional time, develop appropriate instructional strategies, create effective assessment tools, and promote positive attitudes. At the conclusion of the practicum: (1) time spent on science was significantly greater than before; (2) teachers had learned to design science experiences, use activity-based instructional methods, and develop alternative methods of assessment; (3) every student mastered the objectives introduced; and (4) all students who completed the questionnaires responded positively to eight out of the ten statements. Vorsino (1990) attributes the positive student attitudes to the students' successful participation in science experiences and a sense of accomplishment gathered from hands-on activities. Vorsino (1990) supports other researchers who suggest that positive changes in science instruction must begin with the classroom teacher, include teacher-training, and administrative support (Dawes, 1987; Kyle et al., 1988).

\section{Effects of Hands-on Science on Attitude and Achievement}

Hartshorn and Nelson (1990) investigated the effects of hands-on science instruction on the achievement and attitudes of elementary students. Prior to the year long program of science education improvement, 27 four- 
member teams were recruited from nine school districts in 1987,1988, and 1989. All teams received 240 hours of instruction at the Elementary Science Education Institute (ESEI). The content knowledge and attitudes of students with ESEI teachers and non-ESEl were compared in two separate studies. The first study included first and second graders, and the second study included fourth, fifth, and sixth graders.

First and second grade students in both conditions made significant gains in content knowledge, although the ESEI students consistently performed better than the comparison students. The fourth, fifth, and sixth grade ESEI students scored higher than students in the comparison groups at the end of the year. The ESEI condition demonstrated a positive relationship between handson science instruction and achievement, which supported the findings of Jaus (1977), Bredderman (1983), Shymansky et al. (1983), and Shymansky et al. (1986).

The attitude survey was analyzed in two parts because Items 1-12 required forced responses, and items 13-15 were open-ended. First and second grade ESEI students reported more positive attitudes on the Part 1 questions at the end of the year as compared to the beginning. The comparison group reported more negative attitudes at the end of the year as compared to the beginning of the year. Both group's ratings on the open-ended questions became more negative by the end of the year. Attitudes in grades 4-6 supported findings that as students get older, their attitudes become less positive toward science (Yager, 1984). ESEl students' and comparison students' attitudes declined on both parts of the questionnaire from the beginning to the end of the 
year. Fourth grade ESEI students had a significantly higher mean attitude score at the end of the year than the comparison group on both parts of the questionnaire. The fifth grade comparison group had consistently higher scores than the ESEl groups on the pre- and posttest. Sixth grade student attitudes declined from the beginning to end of the school year. However, the ESEI posttest means were significantly higher than those of the comparison group.

Hider and Rice (1988) compared the effects of three science teaching strategies on attitudes and achievement in science. Sixty-five fifth and sixth grade students were randomly assigned to one of four treatment groups: (1) textbook approach, lectures, and follow-up written assignments about scientific content; oriented to left hemisphere processing style; (2) hands-on, use of manipulative materials, covering same content as in Group 1, oriented toward right hemisphere processing style; (3) textual presentation, written assignments, and hands-on strategies; supported both hemispheric processing styles; (4) control group received no instruction on the science content, instead they worked on math and social studies activities.

The three experimental groups (textbook, hands-on, and integrated) indicated significant gains in attitude. The integrated group demonstrated threetimes the attitude gains of the textbook group and hands-on group. The handson group had a larger increase in attitude than the textbook group. Achievement gains were the greatest in the textbook (left hemispheric) group. The hands-on (right hemispheric) group showed the smallest gains in achievement. Although all three experimental approaches resulted in achievement gains, gains were significantly greater in the two groups that included the textbook. The 
researchers note that this gain could be due to the fact that the students were accustomed to using textbook materials in science class.

Hider and Rice (1988) suggested that science teachers combine textbook activities and hands-on activities to promote academic and attitude gains, as well as meet the different learning styles of students. The integrated approach in this study resulted in significant gains in student achievement and the highest increase of all four groups in the area of attitude. Showater (1984) reported that the best method for teaching science included a variety of activities, and that the exclusive use of any one method is not likely to be effective. Borst (1986) found that labs and hands-on experiences, in addition to textbook learning, became the combination tool for students to learn and maintain the science material presented. The integration of hands-on and textbook-based instruction in science has been found to be effective in promoting achievement and attitude gains.

Webb (1986) reported findings from a study conducted to determine how to develop more positive student attitudes toward science and to increase science knowledge. During the school year, second grade students participated in 12 supplemental science learning centers that included hands-on science activities. Attitudes of the participating second grade students toward science were assessed at the beginning of the school year. Following participation in the 12 hands-on learning centers, attitudes were re-assessed.

Data from attitude surveys indicated that students became more positive in their attitudes toward science. After experiencing the learning centers, the percentage of students who responded favorably to statements about science 
rose considerably. Responses of students who had not participated in the learning centers showed a slight rise on the second survey.

Students who participated in the learning center activities increased their knowledge of the major concepts and the science vocabulary in the three chapters covered. There was not a significant difference between pre- and posttest scores overall, although some students who scored low on the pretest showed a marked increase on the posttest. Webb (1986) points out that the duration of this study was too brief to expect a significant difference in pre- and posttest scores and suggested that future research be done to analyze the effects of integrating hands-on and text-based methods on attitudes and achievement over a longer period of time.

\section{Effects of Hands-on Science on Achievement}

Wise and Okey (1983) conducted a meta-analysis including studies that represented research done over a 30 year period, in order to identify the effects of various science teaching techniques on achievement. Results indicated that direct teaching techniques (focusing/questioning) had greater effects on achievement than indirect techniques (inquiry/discovery). Wait-time was found to have the greatest effect on achievement, although the fewest number of studies were reviewed in this category. Findings indicate that an effective science classroom that promotes achievement should include the following: students who are aware of the objectives and receive feedback on their progress toward meeting them; (2) students who are given chances to 
physically interact with materials and participate in a variety of activities; (3) teachers who make changes in instructional materials and classroom procedures; (4) considerable teacher planning takes place, and (5) students have some responsibility for defining tasks.

Yore (1986) investigated the effects of lesson structure and cognitive style on the science achievement of $\mathbf{4 0}$ fourth and fifth graders. Students participated in two instructional treatments with different degrees of structure. In Treatment 1 specific problems were introduced, and then students developed their own experimental procedures and used the available materials to investigate the problem. Treatment 2 provided more lesson structure. Specific problems were introduced, experimental procedures agreed upon, and data tables generated so students could analyze findings during experimentation.

Results of posttests indicated slightly higher achievement for the students participating in the highly structured lessons; although the differences in achievement were not significant. This supports the findings of Wise and Okey (1983) that direct teaching techniques had greater effects on achievement than indirect teaching techniques.

\section{Computer-based}

\section{Box Score Method Reviews}

Reviews of computer research that were conducted between 1970 and 1980 were done using the "box score" method that has been criticized as providing limited and subjective information (Slavin, 1984). To review research 
using the box score method, the reviewer had to (1) collect all the experimental and evaluation studies which compared a computer-based learning treatment with another instructional treatment (usually traditional classroom teacher-led instruction), (2) examine each study to determine whether or not it had found significant differences between the treatments, and (3) count the number of studies that did and did not find such differences (Roblyer et al., 1988).

Vinsonhaler and Bass (1972) used the descriptive method on ten studies of computer use in mathematics and language instruction. The experimental groups received traditional instruction combined with CAI drill-and-practice, and the control group received traditional instruction only. Pre- and posttests were administered to all groups. The results of this study showed a greater gain for all the experimental groups over the control groups in language arts. In the area of mathematics, most of the experimental groups showed greater gains than the control groups. Many of the experimental groups showed significant gains.

Jamison, Suppes, and Wells (1974) reviewed over 20 studies in computer-based methods as part of their review of "alternative instructional media." Jamison et al. (1974) concluded that CAl appeared to be effective as a supplement to classroom instruction for elementary and remedial students, and that "in some situations" it could be used to improve achievement scores for these students.

Edwards, Norton, Taylor, Weiss, and Van Dusseldorp (1975) used the box score method to review 33 studies conducted from 1966 to 1973 that inciuded elementary, secondary, and college students. In this review the studies were classified by seven different criteria in order to compare and contrast 
research findings that involved similar strategies or types of results. Twentyeight of the 33 studies analyzed by Edwards et al. (1975) directly investigated the effect of CAI on achievement. Each of the eight studies that involved CAl as a supplement to traditional instruction demonstrated that traditional instruction combined with CAl was more effective than traditional instruction alone. However, the degree of achievement was not consistent. For example, Suppes (1972, cited in Edwards et al., 1975) found that students gained as much as 2.28 grade levels in computational ability in one year, whereas Arnold (1970) and Scrivens (1970, cited in Edwards et al., 1975) reported a 0.3 grade level gain after one year of traditional arithmetic instruction combined with CAI.

In the 20 studies that substituted CAI for traditional instruction, nine studies showed that the CAl students achieved more than the non-CAl students, eight found little or no difference, and three showed mixed results (Edwards et al., 1975). CAl was found to be more effective at elementary levels and appeared to save learning time. Supplemental uses of CAl appeared to be more effective than replacement uses. When compared to other non-traditional methods (individual tutoring and programmed instruction), CAl seemed to be equally effective.

The Florida Department of Education (1980) reviewed computer research and found some advantage to using CAI at the elementary level. Similar to Jamison et al. (1974) many of the studies found no significant differences. 
Crosby (1983) reviewed studies focusing on the effectiveness of CAI and Computer-Managed Instruction (CMI) with students who had mild learning problems. Many of the studies reviewed had also been included by Jamison et al. (1974) and Edwards et al. (1975). Consistent with these reviews, computer instruction as a supplement to traditional instruction was more effective than computer instruction as a replacement strategy. Crosby (1983) pointed out that very few of the research studies available included microcomputers, which could influence future findings.

\section{Meta-Analyses Reviews}

Glass (1976) introduced meta-analysis, a method of calculating a more precise difference between experimental and control treatments. In metaanalysis, reviewers subtract the impact of the control or traditional method from the impact of the experimental method to estimate the effect the new method would have over the old method.

Hartley (1977) examined studies in elementary and secondary mathematics and was the first to apply meta-analysis to findings on computerbased instruction. Hartley included 22 studies in the analysis. All of the studies utilized either the drill-and-practice or tutorial mode of CAI. The findings indicated that $\mathrm{CAl}$ raised student achievement by 0.41 standard deviations on the average.

Burns and Bozeman (1981) analyzed the results of 40 studies in elementary and secondary mathematics using meta-analysis. The purpose of 
the meta-analysis was to integrate research findings relating to the effectiveness of computer-assisted mathematics instruction on achievement. In order to be included in the meta-analysis the study had to meet six criteria. Results of the meta-analysis suggested the following relationships: (1) supplemental CAI instruction resulted in significantly more achievement than traditional instruction alone; (2) CAI drill-and-practice programs raised the achievement of students in elementary and secondary school regardless of their ability level; (3) boys in grades four through six, using supplemental CAI, achieved significantly higher gains than those taught using traditional methods; and (4) tutorial-supplemented instruction produced significantly higher gains for both elementary and secondary students. Burns and Bozeman (1981) pointed out that these findings are not final answers, since the study investigated only one subject area (mathematics), and two modes of computer use (drill-andpractice and tutorial).

Despite the differences in methodologies used (box-score, and metaanalysis), the findings of Jamison et al. (1974), Vinsonhaler et al. (1972), Edwards et al. (1975), Hartley (1977), and Burns and Bozeman (1981) indicate a positive correlation between supplemental CAI instruction and achievement gains.

\section{Landmark Meta-Analysis Studies}

The following meta-analyses are landmark studies in the field of computer-assisted instruction: Kulik, Bangert and Williams, 1983; Kulik, Kulik and Bangert-Drowns, 1985; Niemiec, Samson, Weinstein, and Walberg, 1987; 
and Roblyer, Castine, and King, 1988. The researchers combined and analyzed findings encompassing over 20 years of investigation, in order to provide a comprehensive, non-biased synthesis of CAI research. Research reviewed included multiple subject areas and modes of computer use.

Kulik et al. (1983) conducted a meta-analysis to assess the effectiveness of computer-based teaching at the secondary level. Fifty-one studies that met the inclusion criteria were selected for further analysis. Results of the metaanalysis not only indicated a positive correlation between CAI and achievement, but also suggested that retention, student attitudes, and amount of time needed to learn were all positively related to CAI. CAI raised students' final exam scores by approximately .32 standard deviations, or from the 50 th to the 63rd percentile. Results on the final examinations were slightly higher in more recent studies and studies that were conducted over shorter time periods. Student scores on follow-up exams taken several months after the end of instruction were raised a small amount. Students who used the computer developed positive attitudes toward the computer and toward the classes they were taking. Eight of the studies suggested that the attitudes of students were more positive in the classes that used CAI. In addition, the amount of time needed for learning was substantially reduced by the computer.

Two additional trends identified by Kulik et al. (1983) and recommended for further investigation were the concept that $\mathrm{CAl}$ tended to be more effective at the secondary level than the college level, and evidence indicating that low- 
achieving students seemed to demonstrate stronger effects than more talented students.

Kulik et al. (1985) conducted a meta-analysis in which they considered research studies published from 1968 to 1984 . The purpose of the study was to investigate achievement scores of control and experimental groups to determine if CAl enhanced learning at the elementary school level. Also analyzed were retention, and changes in attitude toward school subjects and the computer.

Twenty-eight of the 32 studies included in the meta-analysis reported results from CAI drill-and-practice or tutorial instruction. The remaining four studies reported results from $\mathrm{CMI}$. The effects of CAI were found to be more positive than those of $\mathrm{CMI}$. The most obvious positive outcomes of CAl were indicated by the results of achievement tests. Every CAl class scored higher on the examinations than those in the traditional instructional setting. In each of the five studies that reported results from retention tests, the CAI class scored higher than the control class. Only one study gave student attitude results. This study showed a small positive effect of CAl on student attitudes toward mathematics (Kulik et al., 1985).

The finding of Kulik et al. (1983) that CAI affects instructional levels differently was supported by the results of Kulik et al. (1985). The average effect of CAl in elementary school settings was to raise scores by 0.47 standard deviations. In secondary schools the average effect was 0.36 standard deviations (Kulik et al., 1985), and in college the average effect was 0.26 
standard deviations (Kulik \& Kulik, 1985) as reported in Kulik et al. (1985). Further research into why younger students appear to achieve at higher levels than older students could help educators plan age-appropriate lessons.

Kulik et al. (1985) concluded that there was no significant correlation between study characteristics (ability level of students, type of software) and the size of effects. Kulik et al. (1985) note that none of the studies analyzed in this review was microcomputer-based. The researchers suggest that more attention be given to CAl as it affects attitudes toward school and computers, and how CAI contributes to instructional efficiency (learning time and retention). The authors point out that achievement scores have been repeatedly examined, and new avenues of research related to CAI should be conducted.

Niemiec et al. (1987) conducted a meta-analysis to identify both the overall effectiveness of computer-based instruction (CBI) in the elementary school and to identify those groups of students who were most likely to benefit from exposure to CBI. Using the meta-analytic method of Kulik (1981), Niemiec et al. (1987) reviewed studies that covered all subject areas and all forms of $\mathrm{CBI}$. The authors suggested that although previous studies (Burns \& Bozeman, 1981; Jamison et al., 1974; Kulik et al., 1980; Kulik et al., 1983; Vinsonhaler \& Bass, 1972) did report a positive correlation between CAI and achievement, they were limited in scope. Due to the absence of a thorough review of CAI and how it affected elementary students across all subject areas, Niemiec et al. (1987) saw a strong need for a comprehensive analysis of research addressing these issues. It appears that the study of Kulik et al. (1985), which investigated 
the effectiveness of CAl on elementary students, was not available for review at the time this study was being researched. Unlike the meta-analyses done by Kulik et al. (1983) and Kulik et al. (1985), which also investigated the effectiveness of CBI in elementary schools, Niemiec et al. (1987) did not exclude "methodologically flawed" (Niemiec et al., 1987, p. 87) studies from the review. Glass, McGaw, and Smith (1981, cited in Niemiec et al., 1987) report that study quality is a codable variable. Therefore, strong and weak studies were analyzed separately in order to avoid reviewer bias or pre-judgments of study results.

Out of 1,187 studies, 48 met the inclusion criteria and were reviewed in the meta-analysis. Many indications of the overall effectiveness of CAI on elementary students were identified: (1) there appeared to be no connection between year of study publication and effect size; (2) lower achieving students tended to gain more from $\mathrm{CBI}$ than higher achieving students; (3) $\mathrm{CBI}$ was shown to be more effective in the primary grades; (4) drill-and-practice appears to create a greater gain in achievement than higher level tasks, such as reasoning and problem solving; (5) effect sizes indicate that students using the computer have a more positive attitude toward the computer than students in control groups; (6) when achievement gains were measured by standardized tests not specific to treatment, the effect size doubled; (7) tests created by the researchers produced higher effect sizes; (8) studies that were shorter in duration, especially those that lasted two months or less, had higher effect sizes than longer studies; and (9) there appeared to be a relationship between effect 
size and study quality. Experimental studies had smaller differences in effect sizes than did quasi-experimental studies.

Niemiec et al. (1987) like Crosby (1983) and Kulik et al. (1985) pointed out that very few research studies have been microcomputer based, despite the fact that microcomputers are readily available to most school districts. Therefore, a need for microcomputer based research studies was indicated.

The findings of previous researchers (Burns \& Bozeman, 1981; Jamison et al., 1974; Kulik et al., 1983; Kulik et al., 1985; Kulik et al., 1980; Vinsonhaler \& Bass, 1972) who noted a correlation between CAl and achievement gains were validated by the meta-analysis of Niemiec et al. (1987). Also reinforced was the finding of Kulik et al. (1985) that elementary students appear to gain more from CAl than older or middle grade students.

The research studies and meta-analyses discussed above provide a detailed review of the effects of CAl at the secondary and elementary school level. The most documented effect of CAI has been achievement gains (Burns \& Bozeman, 1981; Edwards et al., 1975; Hartley, 1978; Kulik et al., 1983; Kulik et al., 1985; Niemiec et al., 1987; Vinsonhaler \& Bass, 1972). The two metaanalyses that investigated the effectiveness of CAl with elementary students across subject areas and modes of computer use (Kulik et al., 1985; Niemiec et al., 1987) provide a comprehensive summary and comparison of findings from studies representing over 20 years of CAI research.

It is noteworthy that Kulik et al. (1985) and Niemiec et al. (1987) reviewed 17 of the same studies despite differences in the inclusion criteria. This seems 
to indicate that both teams of researchers did a thorough review of literature pertaining to CAl and elementary education. The similarities of their research design, findings on achievement gains, and the indication that younger students achieve more than older students point to the strength of their meta-analyses. An additional strength of these research reviews is the fact that they are current and therefore encompass research studies from 1960, 1970, and 1980.

Roblyer, Castine, and King (1988) conducted a comprehensive review and meta-analysis of computer-based research carried out from 1980 to 1987. The goal was to scientifically summarize the results and identify if there were trends in the findings which may guide future classroom use of computers. The researchers also hoped to establish needs and promising directions for future research. Clark (1985, cited in Roblyer et al., 1988) pointed out that although previous reviews have produced global information to direct the course of computer use in various subject areas and with various target groups, they have over-emphasized the computer's role and have not adequately addressed the potential influence of other factors, including teacher intervention and software quality. in addition, previous reviews rarely provided information about the specific characteristics of studies being reviewed. Therefore, in an effort to provide a more detailed and complete view of findings in the field of computerbased research, the meta-analysis of Roblyer et al. (1988) grouped studies with similar characteristics, such as content areas or grade levels, to address additional factors that may have influenced results. 
Roblyer et al. (1988) pointed out that since 1974 hardware, software, and classroom implementation have undergone dramatic changes: (1) computer implementation is more teacher-oriented than it was prior to microcomputers; (2) there are more microcomputers available than there were computer terminals then; and (3) computer use in the 1980's takes place in a much different context from that of the pre-microcomputer era.

Roblyer et al. (1988) stated that most all reviews conducted from 1975 to 1987 provided evidence that computer-based instruction offered benefits over other methods. The following trends reported by Roblyer et al. (1988) have been established by computer research reviews conducted from 1975 to 1987: (1) eight reviews concluded that computer-based treatments reduced learning time, although most of the studies that investigated learning time focused on higher grade levels; (2) a variety of studies indicated that computer-based instruction positively affects students' attitudes toward computers, and to a smaller degree, attitudes toward subject matter and school learning (Florida Department of Education, 1980); (3) some data have been gathered which investigated how computer-based instruction affects achievement in specific content areas (Burns \& Bozeman, 1981; Roblyer \& King, 1983; Vinsonhaler \& Bass, 1972); (4) tutorials have been found to be more effective than drill-andpractice in some reviews at the secondary level (Burns \& Bozeman, 1981; Roblyer \& King, 1983; Samson et al., 1985), and drill-and-practice programs have been shown to be more effective than tutorials at the elementary level (Burns \& Bozeman, 1981; Niemiec et al., 1987); (5) CAl appears to be most 
effective when used as a supplement to other methods of instruction (Crosby, 1983; Edwards et al., 1975; Kulik et al., 1983; Okey, 1985); (6) six studies found that slow learners at various grade levels make greater gains with computerbased methods than average and high ability students; and (7) computer-based methods appear to be generally more effective at lower grade levels.

The following are summaries of the results of the Roblyer et al. (1988) study which investigated factors, in addition to the computer, that may have influenced findings. (1) Attitude toward the computer had been addressed in previous reviews. However, Roblyer et al. (1988) addressed attitudes toward school, subject matter, and improving self-image since it was felt that these variables more directly influenced learning. The effects for attitude toward school and subject matter were significantly more favorable when CAI was used. This was consistent with previous findings. Three studies addressed the student self-image variable, and the trend was positive. (2) As in previous reviews, CAl was shown to be more effective in teaching mathematics than reading/language skills, although the differences were not significant. Science was the content area that resulted in the highest effect size. However, the results are inconclusive since only four studies focused on science content. (3) The effect of a particular application type could be addressed in the areas of reading and mathematics since these subjects have been studied more thoroughly. Math applications were found to be equally effective. Tutorial reading applications were shown to be slightly more effective than other application types. Although there were not enough science studies available to 
analyze effects of software applications, Roblyer et al. (1988) did note that the positive effects all involved simulations. (4) Unlike previous reviews, this study found that effect sizes were larger at the college and adult level than at the secondary and elementary levels. Elementary effect sizes were larger than the secondary effect sizes. (5) Lower-achieving students had slightly higher effect sizes than average students. The researchers point out that software designed for slow learners may be more effective with them than software designed for the average population, which could have influenced results. No significant differences were found between males and females in the area of achievement. Roblyer et al. point out that data from studies investigating gender differences when using CAl are inconclusive. (6) Few studies were found which focused on computer applications as a total replacement for traditional methods, so the variable of supplemental versus replacement uses was not covered in this review.

Roblyer et al. (1988) identified specific areas of needed research based on the inconclusive nature of the data available from the computer-based research conducted during the 1980's. The following is a summary of areas recommended for further research: (1) the effects of different applications in a variety of skill and content areas, (2) the effects of computer applications in English as a Second Language (ESL), (3) the effects of word processing use, (4) the effects on creativity and problem solving with Logo and CAl, (5) the effects of computer use on attitudes and the drop-out rate, and (6) the effects of computer use on achievement of males compared to females. 


\section{Cooperative Learning}

The goals of cooperative learning groups focus on bringing each member's learning to the maximum while maintaining good working relationships among members (Male, 1988). Members of cooperative learning groups are not simply thrown together, given a task, and expected to successfully complete it. The social, collaborative skills needed to work together effectively are taught by the teacher. When students have been divided into cooperative learning groups and assigned a task, the teacher monitors the groups to make sure the cooperative learning structure is being used.

Based on his review of the research and results of the individual studies he has conducted, Slavin (1987a, 1987b, 1987c) concludes that in order for cooperative learning to be more effective than traditional instruction in promoting achievement gains, the method must include group rewards and individual accountability. Group rewards could be praise, certificates, recognition, or even grades. They are given based on the group performance or based on the sum of individual performances and provide incentive for group members to encourage and provide help to one another in order for the group to succeed (Slavin, 1987b). Individual accountability creates a situation where the group's success is dependent on the individual learning of each group member, and therefore group members need to make sure all students have mastered the material. 
Slavin (1983b) did a comprehensive review of research on cooperative learning and its effect on achievement. Twenty-five of the 28 studies that used cooperative learning methods which incorporated group rewards based on the sum of individual learning performances found significantly greater achievement gains for cooperative learning groups. The three other studies found no differences. It appears that cooperative learning methods that provide group rewards and require individual accountability yield greater achievement gains than cooperative learning methods that are not as complex. However, Slavin (1987a) points out that despite the method used, "cooperative learning almost always produces gains in social outcomes such as race relations; and it has never been found to reduce student achievement in comparison to traditional methods" (p. 9).

A comprehensive meta-analysis of research studies conducted from 1944 to 1982 by D.W. Johnson, R.T. Johnson, and Maruyama (1983) investigated the relationship between goal structures and interpersonal attraction among heterogeneous and homogenous students. The 98 study review indicated the following relationships: (1) cooperation and cooperation with intergroup competition promoted greater interpersonal attraction among heterogeneous and homogeneous individuals than interpersonal competition and individualistic efforts; (2) cooperation promoted greater interpersonal attraction than did cooperation with intergroup competition, and (3) there appeared to be no significant difference between interpersonal competition and individualistic efforts in promoting interpersonal attraction among students. As a 
result of these findings, the researchers assert that educators should use cooperative goal structures with homogenous and heterogeneous students to foster better relationships.

Johnson and Ahlgren (1976) analyzed the relationships between student attitudes toward cooperation and competition and attitudes toward schooling. Cooperativeness was consistently linked to positive attitudes toward schooling at all grade levels. These attitudes included a positive feeling toward school personnel, a belief that teachers cared about the student's learning, a feeling of being accepted by teachers, and the belief that teachers and principals wanted to be the student's friend.

D.W. Johnson, R.T. Johnson, and Anderson (1978) collected data from 8,183 students representing grades four through 12. Cooperation was found to correlate with the following characteristics at all grade levels: intrinsic motivation, active pursuit of clearly defined learning goals, belief that the student's efforts influenced school success, striving to be a good student and get good grades, and a belief that learning new ideas is important and pleasant. Cooperativeness fostered positive attitudes toward peers, especially at the junior high and high school levels. Also, positive attitudes toward peers who were less smart were related to cooperativeness in junior high and high school. This study supported the findings of Johnson \& Ahlgren (1976) that: (1) cooperativeness tends to be correlated with positive attitudes toward schooling and peers, and (2) cooperation and competition are independent social skills, so encouraging one does not suggest the other will be hindered. 
D.W. Johnson and R.T. Johnson (1983) examined 859 students' responses to a classroom climate instrument and found that students who had frequently worked in cooperative learning groups had more positive attitudes toward teachers and peers than students who had not. Johnson and Ahlgren (1976) and Johnson et al. (1978) found that cooperatively structured learning fostered positive attitudes among peers regardless of ability level.

Cooper et al. (1980) conducted a study to investigate the effects of cooperative, competitive, and individualistic experiences on the relationships among heterogeneous peers. Results indicated that cooperative and competitive learning experiences may promote greater attraction among heterogeneous peers than individualistic experiences. Cooperative experiences resulted in greater feelings of acceptance by peers, and more mutual helping among heterogeneous peers. The tendency for boys and girls to separate was the most resistant to change; separation between ethnic groups and ability levels was less resistant to change; and ethnic-resistance appeared to be the easiest to overcome. In a study by R.T. Johnson, D.W. Johnson, Scott, and Ramolae (1985) results indicated that heterogeneous students working in cooperative situations demonstrated more positive cross-sex and crosshandicap relationships than students working in individualistically structured situations.

D.W. Johnson, Maruyama, R.T. Johnson, Nelson, and Skon (1981) reviewed 122 studies using meta-analysis. This was a comparative study done to identify the effectiveness of different instructional strategies on achievement. 
The strategies compared were: cooperation, cooperation with intergroup competition, interpersonal competition, and individualistic goal structures. Results of the meta-analysis indicated that: (1) cooperation exceeded interpersonal competition and individualistic efforts in producing achievement; (2) cooperation with intergroup competition was also more effective in promoting achievement than interpersonal competition and individualistic efforts; and (3) there was not a significant difference between gains in achievement involving interpersonal competitive and individualistic strategies. The reviewers suggest that educators use cooperative learning procedures to promote higher achievement.

Talmage and Pascarella (1984) conducted a three-year study that investigated the influence of cooperative learning strategies on teacher practices, student perceptions of the learning environment, and academic achievement. According to the researchers, previous reviews and metaanalyses included studies of very short duration (Sharan, 1980; Slavin, 1980; Johnson et al., 1981), did not consider the total classroom setting and the staff development required to implement cooperative learning strategies, nor did they address the difficulty in teaching students their roles and responsibilities as a member of a cooperative learning group.

It appeared that through long-term staff development, teachers could successfully learn cooperative goal structuring strategies. Also, teachers in the experimental group seemed to have developed more positive attitudes toward cooperative learning and to use the strategies more frequently than control 
teachers. Previous findings of reviews of cooperative learning (Johnson et al., 1981; Sharan, 1980; Slavin, 1980) that cooperative learning has a positive effect on student and teacher attitudes were reinforced by this study. However, findings in the area of achievement were not. The researchers were not sure that cooperative learning experiences had determined the amount of achievement or if some other factor had played a part. Talmage and Pascarella (1984) pointed out that the quality of teaching, inexperience of the student with cooperative learning, or the fact that some students who had experienced cooperative learning during the first two years were not members of the experimental classroom during analysis, may have influenced achievement results in this study. The researchers suggested that additional studies be conducted to identify affective and cognitive effects of cooperative learning.

Research investigating cooperative learning has revealed a variety of positive outcomes on student achievement, attitudes, and perceptions. Cooperative learning has been shown to be consistently more effective in producing achievement gains than traditional strategies, competitively structured learning, and individualistically structured learning. Numerous research studies suggest that cooperative learning methods which include group rewards and individual accountability frequently result in significantly greater gains in achievement than do traditional methods (Slavin 1987, a,b,c). In addition to promoting positive gains in achievement, cooperative learning has been shown to create positive social gains as well. Students working in cooperative groups have been found to have higher self-esteem, better 
attitudes toward teachers, principals, and schooling in general; are more motivated to succeed in school, and are more accepting of students different from themselves in regards to race, sex, and ability levels (Cooper et al., 1980; D.W. Johnson \& R.T. Johnson, 1974a, 1974b, 1975; Johnson \& Ahlgren, 1983; Slavin, 1987a).

Cooperative learning has been shown to be a potentially effective instructional strategy. However, in order to be successful, (1) teachers need staff development training, (2) students need to be taught social and collaborative skills, and (3) groups need to be monitored regularly. 


\section{CHAPTER III}

\section{METHOD}

\section{Introduction}

This study explored whether the order of two contrasting instructional activities, (1) hands-on experiments followed by a computer simulation or (2) a computer simulation followed by hands-on experiments, made a difference on the achievement levels and attitudes of students working in cooperatively structured groups. Although there is evidence that hands-on science instruction, computer-assisted instruction, and cooperative learning techniques have positive effects on achievement and/or attitudes, little research has been conducted on learning environments in which the three strategies are used as part of an instructional sequence.

A sample of 101 upper elementary students (96 sixth graders, and five fifth graders) in three self-contained science classes completed pre- and posttests that were used to determine whether the order of engaging in contrasting instructional activities affected achievement and attitudes. The activities involved the use of (1) manipulatives to carry out pulley experiments from the F.O.S.S.: Levers and Pulleys kit, and (2) the computer simulation Miner's Cave to investigate how four simple machines can be used to lift heavy loads. The F.O.S.S.: Levers and Pulleys and Miner's Cave activities were experienced in cooperative learning groups. Student attitudes toward the 
F.O.S.S.: Levers and Pulleys kit, the Miner's Cave computer simulation, and their cooperative learning groups were addressed.

\section{Research Questions}

For purposes of review, the research questions investigated in the study are restated:

1. Does the order in which two contrasting instructional activities are experienced affect the attitudes of students toward hands-on instruction and computer-based instruction?

2. Does the order in which two contrasting instructional activities are experienced affect student attitudes toward working in groups?

3. Does the order in which two contrasting instructional activities are experienced affect the perceptions of students toward the hands-on, computerbased, and cooperative learning instructional settings?

4. Does the order in which two contrasting instructional activities are experienced affect achievement?

5 . Is there a relationship between gender and student attitudes?

6 . Is there a relationship between gender and achievement?

\section{Research Population}

The subjects in this study were students from three self-contained science classes at West Valley Elementary School in Sunnyvale, California. West Valley Elementary School is located in, and draws from, a middle to 
upper-middle class neighborhood. Ninety-six of the students were sixth graders and five were fifth graders. The study included 48 females and 53 males.

All subjects in this study had had previous experiences with hands-on science, computer-assisted instruction, and cooperative learning. Although the students had worked in cooperative learning groups for hands-on science experiments, they had not worked in cooperative learning groups at the computer. This was their first experience in which the integration of all three strategies was used to teach a specific area of the science curriculum.

Subjects self-selected their cooperative science teams. Each classroom had eight teams with a gender configuration as follows:

Class One included four all male teams, two all female teams, and two teams with both females and males.

Class Two included three all male teams, three all female teams, and two teams with both females and males.

Class Three included two all male teams, two all female teams, and four teams with both females and males.

All students completed a pretest prior to beginning the six day unit on simple machines.

The science teams were randomly assigned to a treatment condition and were given a pretest meant to assess attitudes and knowledge. All students spent three days working in the hands-on instructional setting with their teammates, and three days working on a computer simulation with their teammates. Teams $1-4$ in each class participated in the hands-on setting for the first three days, and teams 5-8 in each class participated in the computer simulation setting for the first three days. During the last three days, teams $1-4$ 
participated in the computer simulation setting, and teams 5-8 participated in the hands-on setting. One week later all students completed a posttest.

\section{Hands-on Setting: Three Day Instructional Sequence}

Hands-on activities from the F.O.S.S.: Levers and Pulleys kit enabled students to explore how single and movable pulley systems work.

A. Day One: Students worked together to construct single pulley systems that provided advantage. Following free exploration, a single fixed and a single movable pulley system was modeled by the instructor. Students then constructed each of the pulley systems and used a spring scale to measure the amount of effort needed to lift a 240 gram load. Students discovered that the single movable pulley required less effort to lift the load, and that the single fixed pulley reversed the direction of the effort.

B. Day Two: Instructor reviewed the single pulley systems investigated the previous day. Students were asked to construct systems using two pulleys. Following the free explore time, students were shown a diagram of two possible systems. Students constructed the systems and took spring scale readings. C. Day Three: Students were given ten minutes to practice setting up the four pulley systems discovered during the previous two sessions. All students were to take turns setting up each system. Following the practice session, students played the "Pulley Game." One student from each team was responsible to build the system called out by the teacher. The other team members watched, gave advice, and handed materials to the student constructing the system. Each student took turns building the pulley systems. The goal was to construct the correct pulley system in as little time as possible. 


\section{Computer Setting: Three Day Instructional Sequence}

Students used the computer simulation Miner's Cave by M.E.C.C. to explore how four simple machines work.

A. Day One: Instructor introduced the Miner's Cave simulation. Students were told to boot the disk and press 1 to receive information about Miner's Cave and how the four simple machines work. Demonstrations and explanations were provided by the program to show how to use Miner's Cave, how the four machines work, and what the students must do to reach the "Miner's Hall of Fame." If time permitted, they were to return to the main menu and press 2 to begin "Miner's Apprentice." During "Miner's Apprentice," students selected a machine (lever, pulley, ramp, or wheel and axle) and worked together to investigate how it worked. Students decided how to share the keyboard and recording responsibilities. As the teams experimented, they kept track of the number of tries it took for them to lift or move the load, the force given, load size, and machine specific information, such as wheel and axle size and fulcrum position. Teams were given several copies of the record sheets supplied in the Miner's Cave manual to record their data.

B. Day Two: Teams either began or continued gathering data about each of the simple machines presented in the "Miner's Apprentice" section on their record sheets. If time permitted, students were able to begin "Master Miner." During "Master Miner," students applied the knowledge about forces, loads, and mechanical advantage they had gathered during the trial and error attempts of the "Miner's Apprentice" experience. "Master Miner" had the added challenge of a time constraint. Not only did teams have to select the best machine for lifting or moving the load, but they also had to do so in a limited amount of time. Points 
were awarded based on how skillfully students lifted the loads using the force limits presented in each session. Teams received scores and could become part of the "Miner's Hall of Fame." Again, students decided how to share the keyboard and note taking responsibilities.

C. Day Three: Teams continued with "Master Miner" or completed "Miner's Apprentice" and began "Master Miner." Students began developing strategies for using maximum advantage to lift or move heavy carts full of jewels. Students needed to determine which machine was best suited for the job, depending on the conditions given on the screen (cave height, distance cart had to be moved, size of load).

\section{Description of Instruments}

\section{Pre- and Posttest}

The pre- and posttests were designed to ascertain information regarding student attitudes and achievement. A Likert-type scale was used to measure the attitudes of students toward hands-on experiments, using the computer, carrying out science experiments with others, working at the computer with others, feelings about their group's effectiveness, and feelings about student's contributions to the group.

Achievement was measured through pictorial multiple choice questions and responses to open-ended items as described below:

a. The first pictorial multiple choice question asked students to look carefully at four pulley diagrams and circle any of the pulley systems that would work properly. Three of the four pulley systems pictured should have been circled. 
b. The second pictorial multiple choice question appeared only on the posttest. Students read that the two children that sat on each of three seesaws weighed exactly the same. Students were asked to circle the picture that best showed how the seesaws would look when they stopped moving. Students had to use their knowledge of how fulcrum position affects the effort needed to lift an object. c. The first open-ended question required students to give one good reason why it is important to know how to set up pulley systems.

d. The second open-ended question appeared only on the posttest. Students responded to the question: What generally happens to the effort needed to lift a load as the number of pulleys in the system increases?

e. An open-ended problem was included on the pre- and posttest that presented a hypothetical situation in which a strong wind had blown a heavy branch onto their driveway. The student had to find a way to move the branch so the car could be taken out of the garage, and he/she could be taken to his/her best friend's party. Students were instructed to use any combination of the pictured items to move the branch. Students could use drawings and/or words to explain their Plan 1 and Plan 2. Pictured items included: four pulleys, four roller skates, three car tires, a crowbar, wagon, plank, and a rope. 


\section{Hypotheses}

Six pairs of hypotheses corresponding to the six research questions, were addressed in this study.

A. Hypothesis: The order in which two contrasting instructional activities are experienced results in attitude differences toward hands-on and computerbased instruction that are significant at the .05 level.

Null Hypothesis: The order in which two contrasting instructional activities are experienced does not result in attitude differences toward handson and computer-based instruction that are significant at the .05 level.

B. Hypothesis: The order in which two contrasting instructional activities are experienced affects student attitudes toward cooperative learning groups at the .05 level of significance.

Null Hypothesis: The order in which two contrasting instructional activities are experienced does not affect student attitudes toward cooperative learning groups at the .05 level of significance.

C. Hypothesis: Student perceptions of how the F.O.S.S.: Levers and Pulleys experiments, Miner's Cave computer program, and their cooperative learning group helped them learn the science content are influenced by the order in which they experienced the two contrasting instructional activities.

Null Hypothesis: Student perceptions of how the F.O.S.S.: Levers and Pulleys experiments, Miner's Cave computer program, and their cooperative learning group helped them learn the science content are not influenced by the order in which they experienced the two contrasting instructional activities. 
D. Hypothesis: The order in which two contrasting instructional activities are experienced results in achievement differences that are significant at the .05 level.

Null Hypothesis: The order in which two contrasting instructional activities are experienced does not result in achievement differences that are significant at the .05 level.

E. Hypothesis: Gender affects the attitudes of students toward the instructional setting at the .05 level of significance.

Null Hypothesis: Gender does not affect the attitudes of students toward the instructional setting at the .05 level of significance.

F. Hypothesis: Gender affects the achievement of students at the .05 level of significance.

Null Hypothesis: Gender does not affect the achievement of students at the .05 level of significance.

\section{Data Analysis}

\section{Attitude Questions}

Five of the seven Likert-type scale attitude measurements had five possible responses: (1) strongly agree, (2) agree, (3) undecided, (4) disagree, and (5) strongly disagree. A lower mean score indicates more favorable attitudes. Mean scores of students in the hands-on/CAI treatment group and students in the CAl/hands-on treatment group were analyzed using the independent t-test procedure to determine if significant differences at the .05 level existed between the groups. 
Two Likert-type scale attitude measurements had four possible responses: (1) working alone, (2) working with a partner of my choice, (3) working with a group of my choice, and (4) any of the above. Differences in data gathered on the pre- and posttests for these questions were measured by using chi-square analysis and related two-way contingency tables. Findings from these items were not specifically related to a hypothesis addressed in this study. Therefore, results are reported at the end of Chapter IV in the "Additional Data" section.

\section{Achievement Questions}

a. Three of the four pulley systems pictured on the first pictorial multiple choice question which was on both the pre- and posttest would work properly.

Students who did not circle any of the correct pulley diagrams received a score of zero. Scores of one, two, and three were given to students who circled one, two, or three of the correct pulley systems, respectively. Mean scores for the two treatment groups were compared using an independent f-test.

b. The second pictorial multiple choice question appeared on the posttest only. This question investigated students' understanding of levers and had one correct choice. Students who selected the incorrect seesaw received a score of one, and students who selected the correct seesaw received a score of two. Pre- and posttest means for each treatment condition were compared using an independent t-test.

c. Findings gathered on the open-ended question where students were asked to give one good reason why it is important for people to know how to set up pulley systems were scored as follows. Student responses on the pre- and 
posttests were given a score of one if (1) no response was written, (2) "I don't know" was written, or (3) an inaccurate response was written. Student responses on the pre- and posttest were given a score of two if an accurate reason was given. The mean scores for the two treatment groups were compared using an independent t-test.

d. On the posttest, students responded to the question: "What generally happens to the effort needed to lift a load as the number of pulleys in the system increases?" Student responses were given a score of one if: (1) no response was written, (2) "I don't know" was written, or (3) an inaccurate response was written. Student responses were given a score of two if an accurate reason was given. Mean scores of the two treatment conditions were analyzed using an independent $\mathrm{t}$-test.

e. Student responses to the hypothetical situation in which they were asked to use any combination of pictured items to move a large branch that was blocking their driveway were interpreted in an effort to determine students' ability to (1) explain a strategy using words and/or pictures, and (2) to explain their reasons for selecting a particular strategy to move the branch. In addition, the number of strategies that included pulleys on the pre- and posttest were counted, and whether or not they were used correctly was determined.

The data was organized and processed using StatView SE+Graphics ${ }^{\mathrm{TM}}$ statistical program for the Macintosh computer created by Abacus Concepts, Inc., Berkeley, California. 


\section{CHAPTER IV}

\section{RESULTS}

\section{Introduction}

The purpose of this study was to determine whether the order in which contrasting instructional activities are experienced, i.e., hands-on experiments followed by computer-assisted instruction or computer-assisted instruction followed by hands-on experiments, made a difference on the achievement and attitudes of students working in cooperatively structured groups. Students in the hands-on/CAl condition spent three days carrying out hands-on experiments followed by three days using a computer simulation. Students in the CAl/handson condition spent three days using a computer simulation followed by three days carrying out hands-on experiments. Students in both treatment conditions worked in cooperative learning groups throughout the study.

This study investigated subjects' perceptions of the hands-on activities, the computer program that they used, and working in cooperatively structured groups. Student attitudes were measured using Likert-type scales and openended questions. Student achievement was measured using open-ended questions and pictorial multiple choice questions.

In this review of results, data related to each hypothesis will be reported separately. Additional data not directly related to a hypothesis will be reported separately at the end of the chapter. 
1. Hypothesis A. The order in which two contrasting instructional activities are experienced results in attitude differences toward hands-on and computer-based instruction that are significant at the .05 level.

Null Hypothesis A. The order in which two contrasting instructional activities are experienced does not result in attitude differences toward handson and computer-based instruction that are significant at the .05 level.

The two Likert-type questions had a scale of 1 to 5 . A response of one indicates that the student strongly agrees with the statement, a response of two indicates that the student agrees with the statement, a response of three indicates that the student is undecided, a response of four indicates that the student disagrees with the statement, and a response of five indicates that the student strongly disagrees with the statement. Therefore, a lower mean score indicates more favorable attitudes.

A.1 Attitude Toward Hands-on Science The subhypothesis in the null form that the order in which instructional strategies are experienced does not result in attitude differences toward hands-on science that are significant at the .05 level, was supported by this study. Tabie 1 presents the results from the pre- and posttest Likert-type questions addressing student attitudes toward hands-on science. Students responded on a scale from 1 to 5 to the statement, "I enjoy doing hands-on science experiments." The t-test computes a t value of 1.822 comparing the mean pre/post differences between the hands-on/CAl and the CAl/hands-on treatment groups ( 0.222 and -0.043 , respectively). Results reported in Table 1 suggest that the difference between the attitudes toward hands-on science of the two treatment groups is not significant at the .05 level. 
A.2 Attitude Toward Using the Computer The subhypothesis that the order in which instructional strategies are experienced results in attitude differences toward computer-based instruction that are significant at the .05 level, was supported by this study. Table 1 presents the results from the preand posttest Likert-type questions addressing student attitudes toward using the computer. The $₫$ value of 2.153 suggests that the difference between the attitudes toward computer program use of the two treatment groups is significant at the .05 level. The comparison of the mean pre/post differences of the handson/CAl group and CAl/hands-on group ( -0.333 and, -0.128 respectively) indicates that the students in the hands-on/CAl treatment condition have significantly more favorable attitudes toward using the computer following instruction with both kinds of activities.

2. Hypothesis B. The order in which two contrasting instructional activities are experienced affects student attitudes toward cooperative learning groups at the .05 level of significance

Null Hypothesis B. The order in which two contrasting instructional activities are experienced does not affect student attitudes toward cooperative learning groups at the .05 level of significance.

The Likert-type questions had a scale of 1 to 5 corresponding to responses ranging from strongly agree to strongly disagree. Therefore, a lower mean score indicates more favorable attitudes. 
Table 1

\section{Hypothesis A: Responses Reflecting Attitude Toward Hands-on and CAI}

\begin{tabular}{|c|c|c|c|c|c|c|c|c|c|}
\hline & \multicolumn{4}{|c|}{$\begin{array}{l}\text { Hands-on /CAI } \\
n=45\end{array}$} & \multicolumn{4}{|c|}{ 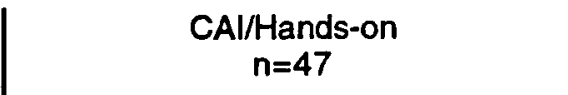 } & \\
\hline & $\begin{array}{l}\text { Pretest } \\
\text { Mean }\end{array}$ & $\begin{array}{l}\text { Posttest } \\
\text { Mean }\end{array}$ & $\begin{array}{l}\text { Differenc } \\
\text { Mean }\end{array}$ & e SD & \begin{tabular}{|l}
$\begin{array}{c}\text { Pretest } \\
\text { Mean }\end{array}$ \\
\end{tabular} & $\begin{array}{c}\text { Posttest } \\
\text { Mean }\end{array}$ & $\begin{array}{c}\text { Differenc } \\
\text { Mean }\end{array}$ & SD & I value \\
\hline $\begin{array}{l}\text { 1) } \\
\text { Attitudes } \\
\text { toward } \\
\text { hands-on } \\
\text { science }\end{array}$ & 1.289 & 1.511 & 0.222 & 0.704 & 1.468 & 1.426 & -0.043 & 0.690 & 1.822 \\
\hline $\begin{array}{l}\text { 2) } \\
\text { Attitudes } \\
\text { toward } \\
\text { using the } \\
\text { computer }\end{array}$ & 1.689 & 1.356 & -0.333 & 1.036 & 1.511 & 1.383 & -0.128 & 1.043 & $* 2.153$ \\
\hline
\end{tabular}

Note: The lower the score, the more favorable the attitude.

* $\quad$ p<.05, two-tailed

The hypothesis that the order in which two contrasting instructional activities are experienced results in significant attitude differences toward cooperative learning groups was supported by this study. Table 2 presents the results of both questions addressing student attitudes toward cooperative learning groups. On the pre- and posttests, students responded to the following statements using a Likert-type scale: "I feel that my group will work successfully together," and "I feel that my group worked successfully together," respectively. The $\mathrm{t}$ value of 2.598 reported in Table 2 is significant at the .05 level, indicating 
that the more positive perceptions of students toward the success of their group in the CAI/hands-on treatment condition is related to the order in which instructional strategies are experienced. There is no difference in the pre/post means in the hands-on/CAl group. The pre/post mean difference for the $\mathrm{CAl} /$ hands-on group is -0.426 .

On the posttest, students responded to the following statement using a Likert-type scale: "I enjoyed working with my group." Table 2 presents the results. The 1 value of 2.112 is significant at the .05 level. The posttest means for the hands-on/CAl and CAl/hands-on treatment condition are 1.933 and 1.542, respectively. The lower, more favorable score of the students in the CAI/handson treatment group indicates that they have more favorable attitudes toward their group members following instruction than those students in the handson/CAl treatment group. 
Table 2

Hypothesis B: Responses Indicating Attitude Toward Cooperative Learning Groups

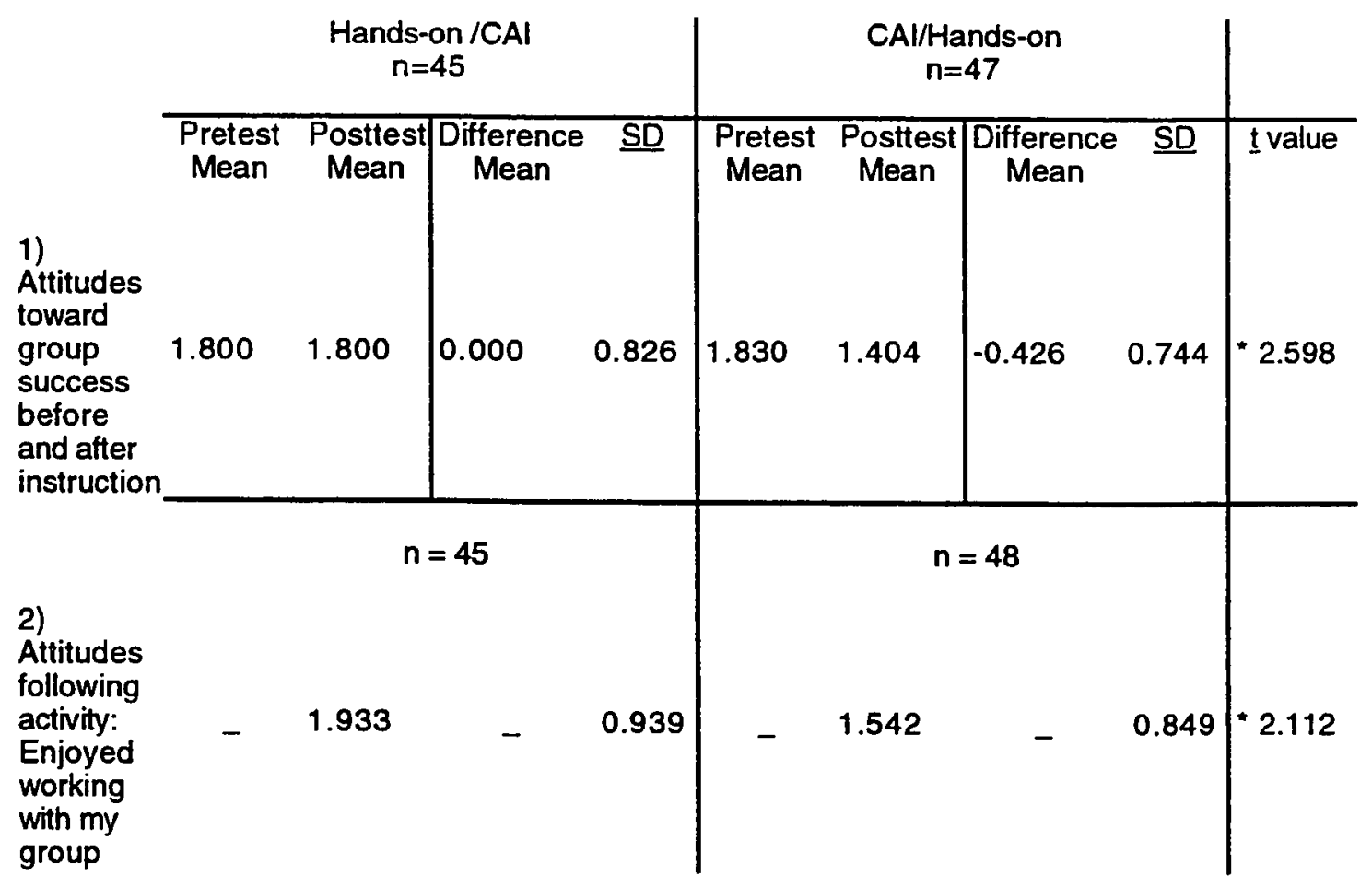

Note: The lower the score, the more favorable the attitude. Dash(-) indicates that data are unavailable for these cells.

- $\mathrm{p}<.05$, two-tailed 
3. Hypothesis C. Student perceptions of how the F.O.S.S.: Levers and Pulleys experiments, Miner's Cave computer program, and their cooperative learning group helped them learn the science content are significantly affected by the order in which they experienced the two contrasting instructional activities.

Null Hypothesis C. Student perceptions of how the F.O.S.S.: Levers and Pulleys experiments, Miner's Cave computer program, and their cooperative learning group helped them learn the science content are not significantly affected by the order in which they experienced the two contrasting instructional activities.

On the posttest, students were asked to rate the F.O.S.S.: Levers and Pulleys hands-on experiments, the Miner's Cave computer program, and working with a group on a scale from 1 to 3 , with number one being the most helpful. Students rated the instructional settings depending on how well each helped them understand what simple machines are and how they work. Some students rated conditions equally indicating that they felt both strategies were equally effective.

The null hypothesis that the order in which students experienced the two contrasting instructional activities will not result in significant differences in student perceptions of how the F.O.S.S.: Levers and Pulleys experiments, Miner's Cave computer program, and their cooperative learning group helped them learn the science content, was supported by this study. Table 3 presents the $t$ values and mean ratings of both treatment groups for the F.O.S.S.: Levers 
and Pulleys experiments, the Miner's Cave computer simulation, and their cooperative learning groups. The $₫$ values for the F.O.S.S.: Levers and Pulleys experiments, the Miner's Cave computer simulation, and cooperative learning are $0.751,0.224$, and 1.635 , respectively. The hands-on/CAl and CAl/hands-on mean rating for the F.O.S.S.: Levers and Pulleys experiments were 1.711 and 1.833, respectively. The hands-on/CAl and CAl/hands-on mean rating for Miner's Cave were 1.733 and 1.771 , respectively. The hands-on/CAl and CAl/hands-on mean rating for working with a group were 2.311 and 2.021, respectively. Results reported in Table 3 indicate that the order in which instructional strategies are experienced does not affect student perceptions of how the F.O.S.S.: Levers and Pulleys hands-on experiments, Miner's Cave computer program, and their cooperative learning group helped them learn about simple machines. 
Table 3

Hypothesis C: Rating of Instructional Strategies as Perceived by Students to Help them Learn Content

1) F.O.S.S.: Levers and Pulleys Experiments

2) Miners Cave Computer Simulation

1.733

0.751

1.771

0.857

0.224

3) Cooperative Learning Group

\begin{tabular}{|c|c|c|c|c|}
\hline \multicolumn{2}{|c|}{$\begin{array}{c}\text { Hands-on/CAI } \\
n=45\end{array}$} & \multicolumn{2}{|c|}{$\begin{array}{c}\text { CAl/Hands-on } \\
n=47\end{array}$} & \multirow[b]{2}{*}{ Ivalue } \\
\hline Mean & $\underline{\mathrm{SD}}$ & Mean & SD & \\
\hline 1.711 & 0.787 & 1.833 & 0.781 & 0.751 \\
\hline 1.733 & 0.751 & 1.771 & 0.857 & 0.224 \\
\hline 2.311 & 0.821 & 2.021 & 0.887 & 1.635 \\
\hline
\end{tabular}

Note: The lower the score, the more favorable the rating.

4. Hypothesis D. The order in which two contrasting instructional activities are experienced results in achievement differences that are significant at the .05 level.

Null Hypothesis D. The order in which two contrasting instructional activities are experienced does not result in achievement differences that are significant at the .05 level.

Achievement was measured using pictorial multiple choice questions and open-ended questions. Higher mean scores indicate higher levels of achievement. The null hypothesis that the order in which two contrasting instructional activities are experienced does not result in achievement 
differences significant at the .05 level, was supported by the responses to the pictorial multiple choice questions used in this study. The findings from both of the pictorial multiple choice questions are reported in Table 4. The first pictorial multiple choice question required students to look carefully at four pulley diagrams and then circle any pulley system that would work properly. Mean scores for the hands-on/CAI treatment group on the pre- and posttest were 2.156 and 3.556, respectively. Mean scores for the CAI/hands-on treatment group on the pre- and posttest were 2.191 and 3.511 , respectively. The $₫$ value of 0.299 is not significant at the .05 level, which suggests that achievement scores are not affected by the order in which two contrasting instructional techniques are experienced.

The second pictorial multiple choice question required students to determine which of three pictures best showed how a seesaw would look when two children of equal weight stopped moving. Students had to use their knowledge of how fulcrum position affects the effort needed to lift an object. The mean scores for the hands-on/CAI group and the CAI/hands-on group were 1.289 and 1.354 , respectively. The $\rfloor$ value of 0.667 is not significant at the .05 level.

The responses to the open-ended questions also supported the null hypothesis that the order in which two contrasting instructional activities are experienced will not result in achievement differences significant at the .05 level. Table 4 reports findings gathered on the open-ended question, in which students were asked to give one good reason why it is important for people to know how to set up pulley systems. Student responses were given a score of 
one if (1) no response was written, (2) the student wrote "I don't know," or (3) the student gave an inaccurate reason. Inaccurate reasons given were: "so people can weigh things," "it will help them know how to pull things," and "so their experiment turns out right." Student responses were given a score of two if the reason was accurate. Accurate reasons given were: "if they need to lift something heavy up," "to lift a load easier," and "if they need to lift something and they have a bad back."

Table 4 reports the $₫$ value of 1.450 which is not significant at the .05 level, indicating that scores are not affected by the order in which two contrasting instructional activities are experienced. The differences between pre- and posttest means for the hands-on/CAl group and the CAl/hands-on group were 0.267 and 0.085 , respectively.

On the posttest, students responded to the question: "What generally happens to the effort needed to lift a load as the number of pulleys in the system increases?" Student responses were given a score of one if (1) no response was written, (2) "I don't know" was written, or (3) an inaccurate response was written. Student responses were given a score of two if an accurate reason was given. The t value of 0.436 , not significant at the .05 level, further supports the null hypothesis that achievement is not affected by the order in which two contrasting instructional activities are experienced. 
Table 4

\section{Hypothesis D: Achievement Results}

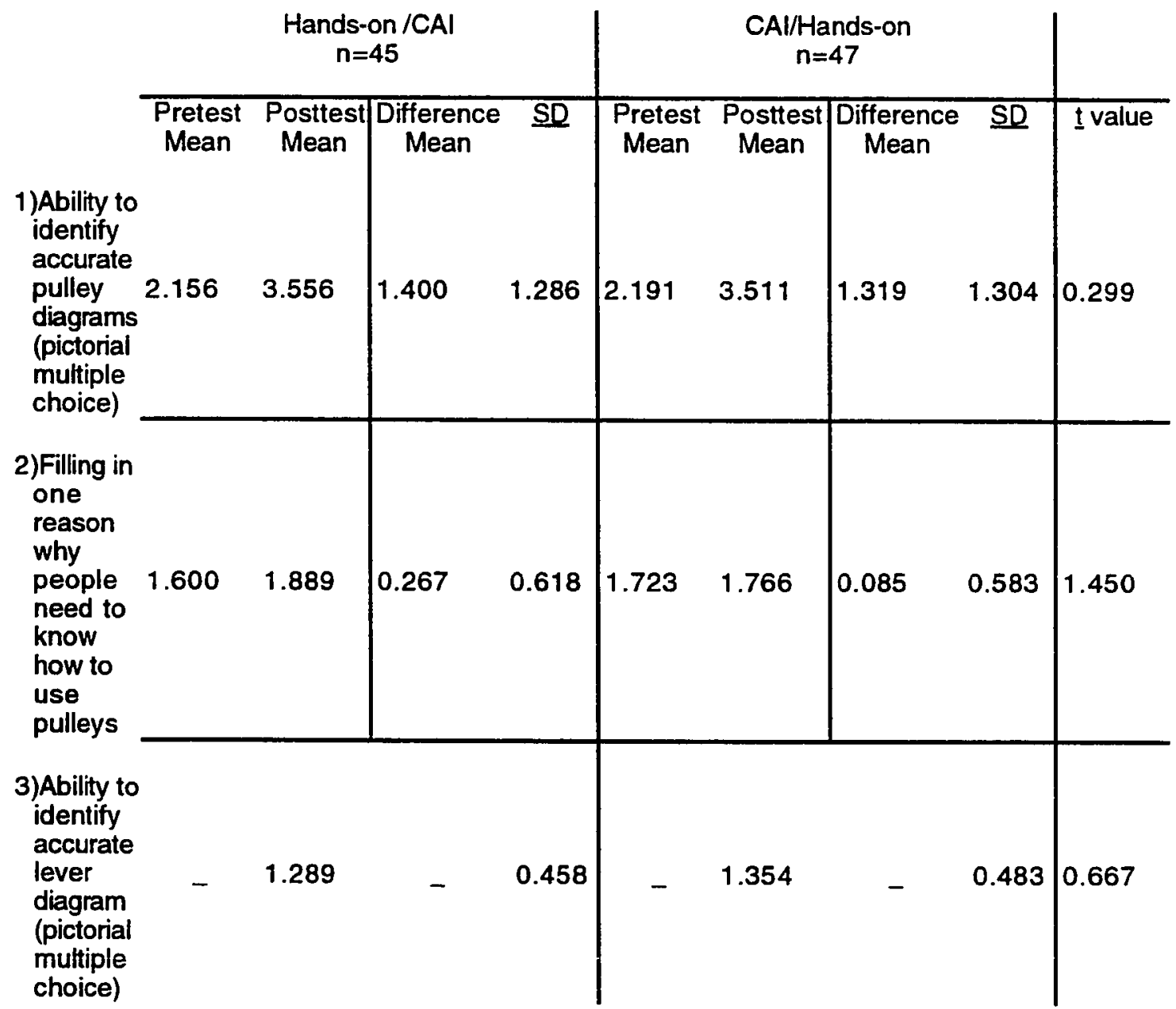

Note: The higher the score, the greater the achievement. Dash (-) indicates that data are unavailable for these cells. 
5. Hypothesis E. Gender affects the attitudes of students toward the instructional setting at the .05 level of significance.

Null Hypothesis E. Gender does not affect the attitudes of students toward the instructional setting at the .05 level of significance.

6. Hypothesis F. Gender affects the achievement of students at the .05 level of significance.

Null Hypothesis F. Gender does not affect the achievement of students at the .05 level of significance.

The nine f-tests done to identify possible differences between male and female attitudes and achievement levels resulted in no differences at the .05 level of significance. These results support the null hypotheses that gender does not affect attitudes and achievement

\section{Additional Data}

Some of the data gathered on the pre- and posttest do not directly relate to a hypothesis but provide additional descriptive information about student preferences and responses to open-ended questions.

\section{Preferences When Doing Hands-on or Computer-based Lessons \\ Using a Likert-type scale, students identified whether they preferred working alone, with a partner of their choice, with a group of their choice, or any of the above when doing hands-on experiments or using the computer.}


Responses were assigned to the following categories: alone, partner, group, and any of the previous. A two-way contingency table was used to investigate whether or not there was a significant difference between the hands-on/CAI group's and CAl/hands-on treatment group's preferences for working alone, with a partner, with a group, or any of the previous.

A. Hands-on Preferences Table 5 shows the preferences of students when doing hands-on lessons. Pre- and posttest results are displayed in the same table. The observed frequency of preferences for working alone, with a partner, with a group, and any of the previous are reported. The chi-square values and degrees of freedom are also reported. The pre- and posttest chisquare values are 1.100 and 4.546 , respectively. Neither of these values is significant at the .05 level, indicating that the order in which contrasting instructional activities are experienced does not affect student preferences for working alone, with a partner, with a group, or any of the previous when doing hands-on lessons. 
Table 5

Preferences When Engaging in Hands-on Activities

Condition Alone Partner Group Any of the $X^{2}$ df

Pretest Results

\begin{tabular}{|c|c|c|c|c|c|}
\hline $\begin{array}{l}\text { 1. Hands- } \\
\text { on then } \\
\text { CAl } \\
n=45\end{array}$ & 5 & 14 & 12 & 14 & 1.100 \\
\hline $\begin{array}{l}\text { 2. CAl then } \\
\text { Hands-on } \\
n=47\end{array}$ & 3 & 15 & 16 & 13 & 1.100 \\
\hline
\end{tabular}

Posttest Results

\begin{tabular}{l|l|l|l|l|l|l}
$\begin{array}{c}\text { 1. Hands-on } \\
\text { then CAI } \\
n=45\end{array}$ & 3 & 18 & 20 & 4 & \\
$\begin{array}{c}\text { 2. CAl then } \\
\text { Hands-on } \\
n=47\end{array}$ & 1 & 13 & 23 & 10 & 4.546 & 3
\end{tabular}

B. Computer-based Preferences Table 6 shows the preferences of students when doing computer-based lessons. Pre- and posttest results are displayed in the same table. The observed frequency of preferences for working alone, with a partner, with a group, and any of the previous are reported. The chi-square values and degrees of freedom are also reported. The pre- and posttest chi-square values are 2.526 and 2.805 , respectively. Neither of these values is significant at the .05 level, indicating that the order in which contrasting instructional activities are experienced does not affect student preferences for working alone, with a partner, with a group, or any of the previous when doing computer-based lessons. 
Table 6

Preferences When Engaging in Computer-based Activities

\begin{tabular}{l|l|l|l|l|l|l} 
Condition & Alone & Partner & Group & $\begin{array}{c}\text { Any of the } \\
\text { Previous }\end{array}$ & $X^{2}$ & df \\
\hline $\begin{array}{c}\text { 1. Hands-on } \\
\text { then CAI } \\
n=45 \\
n=4\end{array}$ & 20 & 17 & 2 & 6 & & \\
$\begin{array}{c}\text { Pretest Results } \\
\text { Hal then } \\
\text { Hands-on } \\
n=47\end{array}$ & 17 & 15 & 3 & 12 & 2.526 & 3
\end{tabular}

\begin{tabular}{l|l|l|l|l|l|l|}
\hline & \multicolumn{5}{|c|}{ Posttest Results } \\
$\begin{array}{c}\text { 1. Hands-on } \\
\text { then CAI } \\
n=45\end{array}$ & 8 & 24 & 8 & 5 & \\
$\begin{array}{c}\text { 2. CAl then } \\
\text { Hands-on } \\
n=47\end{array}$ & 4 & 23 & 12 & 8 & 2.805 & 3
\end{tabular}

\section{Responses to an Open-ended Situation-based Question}

Students were given the following situation on the pre- and posttest: "A strong wind has blown a heavy branch onto your driveway. You must figure out a way to move the branch so the car can be taken out of the garage, and you can be driven to your best friend's party." Students were asked to use any combination of the objects pictured to move the branch. The objects included: a crowbar, wagon, plank, rope, four pulleys, three car wheels, and four roller skates. Students were prompted to use drawings and/or words to explain the plan they would use and why. The pre- and posttests provided space for "Plan 
1" and "Plan 2." The original purpose of this open-ended hypothetical situation was to provide additional information addressing the pair of hypotheses related to achievement. However, a large number of student responses were either vague or only partially complete making it impossible, without interviewing individual students, to interpret what knowledge the students had attempted to convey. At the time these results were being analyzed, students were on summer vacation, making interviewing unrealistic.

Rather than disregard the data collected, results instead were used to investigate students' abilities to (1) explain a strategy using words and/or pictures, and (2) to explain their reasons for selecting a particular strategy. In addition, the researcher wanted to investigate how often pulleys were used on the pre- and posttest, and whether or not they were used correctly.

Strategies and reasoning were given a score of zero through three depending on how detailed and easy to understand they were. A score of zero indicated that the student gave no response. $A$ score of one indicated that the student gave a vague response. Vague responses included some writing and/or drawings but the purpose or thinking was unclear. A score of two indicated that the student gave a partial response. Partial responses included some specific details and/or drawings but were not clearly explained. A score of three indicated that the student gave a detailed response. Detailed responses included specific information and drawings that were clearly explained.

A total of 318 plans for moving the tree branch were collected on the preand posttests. The number of plans collected on the pre- and posttests was 169 and 158, respectively. The mean scores for strategy explanations on the preand posttest were 2.497 and 2.184 , respectively. The mean scores indicate that 
student responses on the pretest were slightly more specific than those on the posttest.

The mean scores for reasoning explanations on the pre- and posttest were 2.012 and 1.730 , respectively. Student responses on the pretest appear to be slightly more descriptive than those on the posttest. The fact that mean scores for strategy explanations are higher than those for reasoning indicate that students are more capable of explaining how to move the branch than they are of explaining why they have chosen a particular strategy. Posttest mean scores for strategy explanations and reasoning explanations were lower than the pretest mean scores.

A total of 318 plans for moving the tree branch were collected on the preand posttests. Twenty-nine percent of the 169 pretest plans included pulleys. Forty-three percent of the 158 posttest plans included pulleys. There was a $14 \%$ increase in the number of responses that included pulleys on the posttest.

The student plans that included pulleys were placed in one of three categories. Category one included pulley plans that would work. Category two included pulley plans that would not work because the pulley was set up incorrectly. Category three included pulley plans that did not include enough information to be understood. On the pretest, $47 \%$ of the pulley plans attempted were accurately set up and clearly explained. Thirty-nine percent were set up incorrectly, and $14 \%$ did not include enough specific information to be understood. On the posttest, $66 \%$ of the pulley plans attempted were accurately set up and clearly explained. Seventeen percent were set up incorrectly, and $16 \%$ did not include enough specific information to be understood. There was a $19 \%$ increase in the number of accurately set up and clearly explained pulley 
plans from the pre- to posttest. There was a $22 \%$ decrease in the number of incorrect set ups from the pre- to posttest.

\section{Summary of Results}

Table 7 summarizes the findings of the study by listing the six pairs of hypotheses and indicating whether the results support or do not support each hypothesis.

Table 7

\section{Summary of Results}

\section{Hypothesis Pairs}

a.1 Hypothesis. The order in which two contrasting instructional activities are experienced results in attitude differences toward hands-on instruction that are significant at the .05 level.

Null Hypothesis. The order in which two contrasting instructional activities are experienced does not result in attitude differences toward hands-on instruction that are significant at the .05 level.

a.2 Hypothesis. The order in which two contrasting activities are experienced results in attitude differences toward computer-based instruction that are significant at the .05 level.

Null Hypothesis. The order in which two contrasting activities are experienced does not result in attitude differences toward computer-based instruction that are significant at the .05 level.
Results

not supported

supported

supported

not supported 
b. Hypothesis. The order in which two contrasting instructional activities are experienced affects student attitudes toward cooperative learning groups at the .05 level of significance.

Null Hypothesis. The order in which two contrasting instructional activities are experienced does not affect student attitudes toward cooperative learning groups at the .05 level of significance.

c. Hypothesis. Student perceptions of how the F.O.S.S.: Levers and Pulleys experiments, Miner's Cave computer simulation, and their cooperative learning group helped them learn the science content are influenced by the order in which they experienced the two contrasting instructional activities.

Null Hypothesis. Student perceptions of how the F.O.S.S.: Levers and Pulleys experiments, Miner's Cave computer simulation, and their cooperative learning group helped them learn the science content are not influenced by the order in which they experienced the two contrasting instructional activities.

d. Hypothesis. The order in which two contrasting instructional activities are experienced results in achievement differences that are significant at the .05 level.

Null Hypothesis. The order in which two contrasting instructional activities are experienced does not result in achievement differences that are significant at the .05 level.

e. Hypothesis. Gender affects the attitudes of students toward the instructional setting at the .05 level of significance.

Null Hypothesis. Gender does not affect the attitudes of students toward the instructional setting at the .05 level of significance.

f. Hypothesis. Gender affects the achievement of students at the .05 level of significance.

Null Hypothesis. Gender does not affect the achievement of students at the .05 level of significance.

supported

not supported

not supported

supported

not supported

supported

not supported

supported

not supported

supported 


\section{CHAPTER V}

\section{SUMMARY AND DISCUSSION}

\section{Overview of Study}

The primary purpose of this study was to explore whether the order of contrasting instructional activities, (1) hands-on experiments followed by a computer simulation or (2) a computer simulation followed by hands-on experiments, made a difference on the attitudes and achievement of students working in cooperatively structured groups learning about simple machines. In addition, the effects of gender on student attitudes and achievement were investigated.

Three classes with 101 upper elementary students (96 sixth graders, and five fifth graders) at West Valley Elementary School in the Cupertino Union School District participated in the study. Students in both treatment conditions completed a pretest, participated in six periods of science instruction (three of which were computer-based and three of which involved hands-on experimentation), and then completed a posttest.

The results addressed six research questions. Four of them considered whether the order in which instructional approaches were experienced affected (1) the attitudes of students toward hands-on science and computer-assisted instruction; (2) student attitudes toward working in cooperative learning groups; (3) how students rated the hands-on, computer-based, and cooperative learning instruction; and (4) the achievement of students. Two of them 
considered whether there was a relationship between (1) gender and attitudes, and (2) gender and achievement.

\section{Attitude Findings: Summary and Discussion}

\section{Summary of Attitude Results}

In comparing attitudes between the two treatment groups, results were found to be significant at the .05 level in the following cases: (1) students in the hands-on/CAI treatment condition had significantly more favorable attitudes toward using the computer following instruction than did the students in the CAl/hands-on treatment condition; (2) students in the CAl/hands-on treatment condition had significantly more favorable attitudes toward group success following instruction, and significantly more favorable responses to the posttest statement, "I enjoyed working with my group," compared to the students in the hands-on/CAl treatment condition.

\section{Discussion of Significant Attitude Results}

\section{A. Attitudes Toward Hands-on Science and Computer Use}

Students in the hands-on/CAl treatment condition had significantly (.05) more favorable attitudes toward using the computer following instruction than did the students in the CAI/hands-on treatment condition. Shaw and Okey (1985) found that a computer simulation combined with hands-on instruction did not result in positive effects on student attitudes, a result which they attributed to the short duration of their study and the fact that the students in the study were accustomed to computer use. Students in this study were not accustomed to 
computer use as an adjunct to science instruction, and both treatment conditions worked with a computer simulation during part of this study. Therefore, if computer use were going to affect attitudes, one would expect both groups to experience similar changes in attitude. In this study, attitudes toward the computer improved, but significantly only for the hands-on/CAI treatment condition.

There may be additional factors that caused the hands-on/CAI group to have significantly more favorable attitudes toward the computer. Students in the hands-on/CAl group first worked together in an instructional approach that was familiar to them (hands-on experiments) and were successful, which could have influenced their later success working together cooperatively in the less familiar computer setting. In addition to the newness of the computer setting, the Miner's Cave computer simulation exposed the students to four simple machines, not just levers and pulleys, which had been investigated in the F.O.S.S. kit. The hands-on/CAl group had the opportunity to bond or work successfully as a group in the hands-on setting prior to working with the more complex, unfamiliar computer setting. This may have enabled the hands-on/CAI group to cooperate with one another and enjoy the computer setting more than the students in the $\mathrm{CAl} /$ hands-on group. The students in the hands-on/CAl group had an opportunity to master levers and pulleys prior to working on the computer simulation. This may have enabled them to feel more successful working with the computer simulation since they were already familiar with two of the simple machines. The CAl/hands-on group may have less favorable attitudes toward using the computer because they were initially faced with (1) the unfamiliar situation of working in a cooperative group at the computer, (2) a program that 
introduced three simple machines that they may not have been familiar with, and (3) the computer setting that provided limited space.

\section{B. Attitudes Toward Cooperative Learning Groups Students in} the CAl/hands-on treatment condition had significantly more favorable attitudes toward their cooperative learning groups' success following the study than did those in the hands-on/CAl group. The attitudes of the students in the handson/CAl group remained constant from the pre- to posttest, whereas the attitudes of the $\mathrm{CAl} /$ hands-on group became more favorable between the pre- and posttests. Recency of an experience, familiarity with an instructional approach, and complexity of activities each may have influenced student attitudes toward their cooperative learning group. The fact that the CAl/hands-on group ended the study with the hands-on instructional approach that they were familiar with may account for their more favorable attitudes toward their group. Conversely, the hands-on/CAl group ended the study with the unfamiliar, more complex computer simulation approach where space was limited, which could account for their less favorable attitudes toward their group members.

Students in the CAl/hands-on treatment condition also demonstrated significantly more favorable attitudes toward their cooperative group members following instruction than did those students in the hands-on/CAl treatment condition. This more favorable attitude could again be attributable to the fact that the CAl/hands-on group ended the study working together on hands-on experiments. Students were more familiar with the hands-on approach, they had more space to carry out their tasks, and the hands-on activities were less complex than the Miner's Cave program. 


\section{Factors that may have Influenced Attitude Findings}

Although there were significant differences at the .05 level between treatment groups in the area of attitudes, these scores could have been influenced by the following factors: (1) students had not had previous experience working in cooperative groups at the computer; (2) students had not had previous experiences in an instructional unit in science using hands-on experiments in combination with a computer simulation; (3) when students were working on the computer simulation, they were experiencing two novel situations: working in cooperative teams at the computer and using a computer simulation to learn about or reinforce science content; (4) the Miner's Cave computer simulation allowed children to investigate four simple machines, and the F.O.S.S. Levers and Pulleys kit allowed children to investigate only two simple machines, and (5) personality conflicts existed among some members of cooperative learning groups.

\section{Cooperative Learning at the Computer: Student Responses}

Researcher observations and student responses collected during the study revealed conditions of the computer setting that may have affected results. The students who participated in this study had had several experiences working in cooperative learning groups while doing hands-on science experiments. However, this was their first time working in cooperatively formed groups at the computer. The physical limitations of the computer setting did create some frustration among group members. Some teams had a difficult time taking turns at the keyboard, recording notes, and involving all members in planning strategies. On day two of the computer setting, the researcher asked 
teams: "How do you feel about working in cooperative teams at the computer?" and "Can you explain why you feel that way?"

Sample responses in favor of the group were: (1) "Group is good because if I get stuck I'm not stranded." (2) "Like group because I get to know people better." (3) "Like the teamwork." (4) "Like group because it's fun and you get more opinions." (5) "I like to work better in a group, because you get answers right."

Sample responses in favor of working with a partner were: (1) "Two people would be better because we need a bigger space. It's too crowded." (2) "Like to be with a partner because you get more turns. Don't want to be alone. Can discuss and learn more with a partner." (3) "Two people. Four is too many because you can't please everyone. They get on your case." (4) "Smaller group is good. If you don't understand, another person can help you."

Sixteen students felt that it would be better to work at the computer alone. Sample responses in favor of working alone included: (1) "I'd like to be alone, because l'd go a little slower and would enjoy it more." (2) "Rather be alone, because it's hard to cooperate." (3) "Like to be alone, because I want the computer to myself."

The pre- and posttest information on preferences when working at the computer, combined with the information gathered in the interviews during day two, indicate that working with a partner or a group at the computer is preferred to working alone by most of the students involved in this study. 


\section{Student Ratings of Instructional Approaches}

On the posttest, students were given the opportunity to rate the instructional approaches that they encountered during the study. Findings indicate that the hands-on experiments and the computer simulation were perceived by both treatment conditions to be slightly more instructive than their cooperative learning group. No significant differences were found between groups in terms of how students rated the effectiveness of the F.O.S.S.: Levers and Pulleys experiments, the Miner's Cave computer simulation, and their cooperative learning group in helping them learn about simple machines.

This is interesting when one considers that the hands-on/CAl group had significantly more favorable attitudes toward the computer setting on the Likerttype question that appeared on the pretest and posttest. The difference in results for similar questions answered by the same students could have been influenced by the question type. The Likert-type questions that appeared on the pre- and posttests required a forced response on a scale from 1 to 5 to the statements: "I enjoy using the computer;" and "I enjoyed using the computer software Miner's Cave." The rating question appeared on the posttest only and was open-ended in nature. Students were asked to rate the hands-on experiments, computer simulation, and their cooperative learning group on a scale of 1 to 3 , with one being the most favorable. The intent of the question was for each approach to be assigned either a one, two, or three. Instead, many students used all ones, two ones, or a combination of twos and ones. In fact, several students rated F.O.S.S.: Levers and Pulleys experiments and the Miner's Cave computer simulation equally. It is apparent that the rating question needed to be clarified to achieve discrimination among responses. Interviews 
with the students following the posttest could have clarified student's interpretations of the rating question.

\section{Achievement Findings: Summary and Discussion}

No significant differences were found for achievement between the treatment groups on either the pictorial multiple choice or the open-ended questions. Previous research has shown the positive achievement effects of supplementing science instruction with simulation software (Choi \& Gennaro, 1987; DeClercq \& Gennaro, 1987; Rivers \& Vockell, 1988; Roblyer et al., 1988;

Shaw \& Okey, 1985). In addition, computer-simulated experiments have been found to be as effective as hands-on experiments in terms of achievement gains (Cavin \& Lagowskil, 1978; Choi et al., 1987; Jones, 1972). The results of this study suggest that the order in which instructional approaches are experienced (1) hands-on experiments followed by a computer simulation or (2) a computer simulation followed by hands-on experiments will not affect student achievement.

This finding seems logical in light of previous research findings investigating the effects of hands-on and computer-based approaches on achievement in science, however; additional research, particularly looking for long term effects, must be conducted before a generalization can be made. The short duration of this study and the fact that it included only one science content area may have influenced the achievement results. A longer study covering various science topics would provide achievement information for science content that may not be enhanced by both instructional approaches. Simple 
machines may lend themselves to both hands-on and CAl instruction, which may not transfer to other science topics.

Interviews with the students could have enabled the researcher (1) to clarify whether the achievement questions were understood, and (2) to elicit student explanations of their drawings and written responses. Research that compares achievement results when strategies are used alone and as a sequence of instruction need to be conducted to identify possible achievement effects. It would be interesting to investigate achievement over a longer period with different science topics.

\section{Gender Findings: Summary and Discussion}

No significant differences at the .05 level were found between males and females on either attitudes or achievement. In this study, gender did not appear to affect attitude or achievement.

Gender differences may have been minimized because: (1) students worked in cooperative learning groups; (2) students were given the opportunity to self select their cooperative group members; (3) students used approaches that appeal to different learning styles; and (4) the cooperative computer setting was new to the students. Choi and Gennaro (1987) identified a tendency for boys to benefit more from hands-on experiments, and for females to benefit more from the computer-simulated experiences. The inclusion of both instructional approaches as part of a learning sequence may have hidden that tendency in this study. The lack of gender differences could also be related to 
the fact that students in this study were younger than those in the Choi and Gennaro (1987) study.

\section{Additional Findings: Summary and Discussion}

The results reported in this section do not directly relate to the questions set forth in the study. However, they do provide additional descriptive information about (1) student preferences when engaged in hands-on and computer-based activities and (2) responses to an open-ended hypothetical situation.

\section{Preferences}

No significant differences were found between treatment conditions in terms of student preferences for (1) working alone, (2) working with a partner of their choice, (3) working with a group of their choice, or (4) any of the above. Students in both treatment conditions appear to find working alone to be least desirable when conducting hands-on experiments and working on computerbased activities.

If the students had not been given a chance to select their teams, these results may have been different. Random groups of students may have experienced more conflict among members and lack of productivity, which could have resulted in more students wanting to work alone.

Researcher observations during class activities indicated that students were focused in both instructional settings. Conflict was observed only in the computer setting and was reported by students to have been the result of being 
to close together or cramped. Future research involving cooperative work at the computer should be carried out in an environment that provides adequate space for chairs and movement of students.

\section{Responses to an Open-ended Situation-based Question}

Student's explanations of their strategies and reasons for selecting a particular strategy for moving a tree branch were slightly more specific on the pretest than they were on the posttest. The posttest was completed two weeks prior to summer vacation, a factor that may have affected the quality of strategy explanations on the posttest. The number of plans that incorporated pulleys increased by $14 \%$ from the pre- to posttest. On the posttest $66 \%$ of the pulley plans attempted were accurately set up and explained, compared to $47 \%$ on the pretest. The number of incorrect responses went from $39 \%$ on the pretest to $17 \%$ on the posttest.

In reflecting on students' abilities to explain strategies and their reasoning, this study indicates students are more capable of describing how to do something than they are of describing their own thinking. More specifically, results indicated that students are more capable of explaining how to carry out their strategy than they are of explaining why they have chosen a particular strategy. This could be a result of students normally being graded based on correct and incorrect responses, rather than being given credit for reasoning. Teachers who expect students to explain their reasoning need to teach children how to do so. 


\section{Classroom Implications}

Previous research has shown the positive achievement effects of supplementing science instruction with simulation software (Choi \& Gennaro, 1987; DeClercq \& Gennaro, 1987; Rivers \& Vockell, 1988; Roblyer et al., 1988; Shaw \& Okey, 1985). Computer-simulated experiments have also been found to be as effective as hands-on experiments in terms of achievement gains (Cavin \& Lagowskil, 1978; Choi et al., 1987; Jones, 1972). Hands-on science has been shown to have positive effects on attitudes (Dawes, 1987; Jaus, 1977; Kyle et al., 1988; Vorsino, 1990) and achievement (Hider \& Rice, 1988; Wise \& Okey, 1983; Yore, 1986). Shaw and Okey (1985) found that a computer simulation combined with hands-on instruction did not result in significant positive effects on student attitudes, a finding which they attributed to the short duration of their study and the fact that the students in the study were accustomed to computer use. The results of this study suggest that the order in which these instructional approaches are experienced (1) hands-on experiments followed by a computer simulation or (2) a computer simulation followed by hands-on experiments will not have harmful effects on either student attitudes or achievement.

A common problem for teachers who would like to use computer simulations and hands-on experiments to improve science instruction is the limited number of computers and hands-on science supplies in their classrooms. If students are not put at a disadvantage by the order in which they experience hands-on experiments or a computer simulation, as this study 
suggests, teachers will be given an efficient option for utilizing limited numbers of computers and/or hands-on science supplies to teach science concepts. Teachers can have half of their class work in cooperative teams on hands-on experiments and the other half of the class work in cooperative teams on a computer simulation. The two groups can then trade places and participate in the setting in which they have not yet worked. Observations and studient responses gathered in this study reveal that ample physical space should be provided when students work in cooperative groups at the computer.

\section{Implications for Further Research}

Student responses on open-ended questions were often vague and difficult to interpret. Future research should include the use of interviewing for clarification of students' answers, and to identify factors that may have influenced their responses, such as (1) not understanding the question, (2) mood the day of the pre- and/or posttest, (3) personality conflicts among members of the group, (4) disinterest in content, and (5) amount of experience working in cooperative learning groups in a particular instructional setting. Follow up studies that incorporate interview techniques would enable researchers to investigate the reasons that students responded as they did to attitude and achievement questions.

This is only one study of one school with one particular student population and community. Additional studies are needed to determine whether the effects on attitudes and achievement are similar for students with different backgrounds and from different communities. If findings on this study and others 
are consistent, then teachers with limited numbers of computers and hands-on equipment can maximize the use of materials and provide science instruction that appeals to various learning styles, knowing that the order in which instructional approaches are experienced probably will not have a negative effect on student attitudes and achievement.

This study was short in duration and included only one science content area simple machines. Students experienced working in cooperative groups at the computer for the first time and the use of more than one instructional approach to learn science content for the first time. In addition, limited space was provided for the computer-based groups to work. These and other factors may have influenced the results of this study.

Studies that are longer in duration need to be conducted to determine whether (1) the novelty of the computer situation has an effect on attitude and achievement results; and (2) the attitude and achievement results are consistent when other science topics are covered using hands-on experiments followed by a computer simulation, or a computer simulation followed by hands-on experiments. In particular, studies of longer duration could investigate whether attitude and achievement effects remain favorable from the beginning to the end of the year, as students become equally familiar with the hands-on approach and computer simulation approach and are exposed to various science topics.

The order in which instructional approaches were experienced in this study did not have negative effects on either attitude or achievement. It is possible that hands-on experiments only or computer-based activities only could result in greater gains for either attitudes or achievement than when the two approaches are used in a sequence, and the two effects could neutralize 
each other in a combined approach study such as this one. To find out, research comparing differences in attitude and achievement effects in the four instructional settings listed below could be carried out: (1) hands-on experiments only, (2) computer-based activities only, (3) hands-on experiments followed by computer-based activities, and (4) computer-based activities followed by hands-on experiments. Research that addresses these issues enables teachers to make informed choices when selecting approaches for teaching various science topics. Considering the diversity of preferences within classes, however, and the recognized value of using multiple approaches, evidence that supports academic success and positive attitudes as independent of activity order is good news for teachers with limited resources.

\section{Conclusion}

This study explored whether the order of instructional approaches (1) hands-on experiments followed by a computer simulation or (2) a computer simulation followed by hands-on experiments, made a difference on the attitudes and achievement of students working in cooperatively structured groups. Although there is evidence that hands-on science instruction, computerassisted instruction, and cooperative learning techniques have positive effects on achievement and/or attitudes, little research has been conducted in which the three strategies are used in an instructional unit and the affects on attitude and achievement investigated.

Results of this study that were significant at the .05 level were: (1) students in the hands-on/CAl treatment condition had significantly more 
favorable atiitudes toward using the computer following instruction than did students in the CAl/hands-on treatment condition; (2) students in the CAI/handson treatment condition had significantly more favorable attitudes toward group success following instruction than did students in the hands-on/CAI treatment condition; and (3) students in the CAl/hands-on treatment condition had significantly more favorable responses to the posttest statement, "I enjoyed working with my group," when compared to students in the hands-on/CAI treatment condition.

No significant differences were found between treatment conditions (1) on attitudes toward hands-on science, (2) in terms of how students rated the effectiveness of the F.O.S.S.: Levers and Pulleys experiments, the Miner's Cave computer simulation, and their cooperative learning group in helping them learn about simple machines, or (3) on either the pictorial multiple choice achievement questions or the open-ended achievement questions.

When carrying out hands-on experiments and computer simulations, students in both treatment conditions appear to prefer working with a partner or a group to working alone. No significant differences were found between males and females on attitude or achievement measures. Results indicated that students are more capable of explaining how to carry out their strategy than they are of explaining why they have chosen a particular strategy to solve a problem.

This investigation supports the notion that negative effects on attitude and achievement are not related to the order in which contrasting instructional activities are experienced by students working in cooperative learning groups to learn science content. It is feasible to have cooperative groups of students 
carrying out hands-on experiments followed by a computer-simulation, while other cooperative groups of students work with a computer simulation followed by hands-on experiments to learn science content. This organizational strategy is important as a way to cope with limited numbers of computers and hands-on science supplies. Further research is recommended to identify the variety of variables that influence success in this kind of setting. 


\section{REFERENCES}

Aiello, N. C., \& Wolfle, L. M. (1980). A Meta-Analysis of Individualized Instruction in Science. Paper presented at the annual meeting of the American Educational Research Association. (ERIC Documuent Reproduction Service No. ED 190 404).

Allen, C. A. (1988). Social Interactions Between a Teacher and Small Groups of Students Working with a Microcomputer. Computers in the Schools, 5, 271284.

Anderson, R. D. (1983). A Consolidation and Appraisal of Science MetaAnalyses. Journal of Research in Science Teaching, 20, 497-509.

Balajthy, E. (1989). Computers in Reading: Special Topics of Contemporary Research. Englewood Cliffs, NJ: Prentice Hall.

Battista, M. T., \& Steele, K. J. (1984). The Effect of Computer-Assisted and Computer Programming Instruction on the Computer Literacy of High Ability Fifth Grade Students. School Science and Mathematics, 84, 649-658.

Beasley, W. A. (1985). The Role of Microcomputers in the Education of the Gifted. Roeper Review, 7, 156-159.

Becker, H. J. (1984). School Uses of Microcomputers: Report \#6 from a National Survey. Journal of Computers in Mathematics and Science Teaching, 4, 42 49.

Bell, T. E. (1983). My Computer, My Teacher. Personal Computing, 7, 120-127.

Boettcher, J. V. (1983). Computer-Based Education: Classroom Application and Benefits for the Learning-Disabled Student. Annals of Dyslexia, 33, 203219.

Borst, R. A. (1986). A Cognitive Stimulation. The Science Teacher, 22-27.

Bredderman, T. (1983). Effects of Activity-based Elementary Science on Student Outcomes: A Quantitative Synthesis. Review of Educational Research, 53, 499-518.

Brown, J. W. (April 1986). Some Motivational Issues in Computer-Based Instruction. Educational Technology, 27-29. 
Burns, P. K., \& Bozeman, W. C. (1981). Computer-Assisted Instruction and Mathematics Achievement: is There a Relationship? Educational Technology, 21, 32-39.

Campbell, P. B. (1983). Computers in Education: A Question of Access: Access to Computers. Montreal, Canada. (ERIC Document Reproduction Service No. 233 684).

Cannon, R. K. J., \& Simpson, R. D. (1985). Relationships among Attitude, Motivation, and Achievement of Ability Grouped, Seventh-Grade, Life Science Students. Science Education, 69, 121-138.

Carrier, C., Post, T. R., \& Heck, W. (1985). Using Microcomputers with FourthGrade Students to Reinforce Arithmetic Skills. Journal for Research in Mathematics Education, 16, 45-51.

Cavin, C. S., \& Lagowskil, J. J. (1978). Laboratory Experiments and Student Aptitude on Achievement and Time in a College General Chemistry Laboratory Course. Journal of Research in Science Teaching, 15, 455-463.

Cavin, C. S., Cavin, E. D., \& Lagowskil, J. J. (1981). The Effect of ComputerAssisted Instruction on the Attitudes of College Students Toward Computers and Chemistry. Journal of Research in Science Teaching, 18, 329-333.

Choi, B., \& Gennaro, E. (1987). The Effectiveness of Using Computer Simulated Experiments on Junior High Students' Understanding of the Volume Displacement Concept. Journal of Research in Science Teaching, 24, 539552.

Clark, R. E. (1984). Research on Student Thought Processes During ComputerBased Instruction. Journal of Instructional Development, 7, 2-5.

Clements, D. H., \& Nastasi, B. K. (1985). Effects of Computer Environments on Social-Emotional Development: Logo and Computer-Assisted Instruction. Computers in the School, 2, 11-31.

Condry, J., \& Keith, D. (1983). Educational and Recreational Uses of Computer Technology: Computer Instruction and Video Games. Youth \& Society, 15, 87-112. 
Cooper, L., Johnson, D. W., Johnson, R., \& Wilderson, F. (1980). The Effects of Cooperative, Competitive, and Individualistic Experiences on Interpersonal Attraction Among Heterogeneous Peers. The Journal of Social Psychology, $111,243-252$.

Cox, D. A., \& Berger, C. F. (1985). The Importance of Group Size in the Use of Problem-Solving Skills on a Microcomputer. Journal of Educational Computing Research, 1 , 459-468.

Crosby, H. M. (1983). The Effectiveness of the Instructional Use of Computers for Students with Minor Learning Problems: A Review of Literature and Research. University of Illinois at Urbana-Champaign. (ERIC Document Reproduction Service No. ED 249 688).

Dalton, D. W. (1990). The Effects of Cooperative Learning Strategies on Achievement and Attitudes During Interactive Video. Journal of ComputerBased Instruction, 17, 8-16.

Dalton, D. W. (1990). The Effects of Cooperative Learning Strategies on Achievement and Attitudes During Interactive Video. Journal of ComputerBased Intstruction, 17, 8-16.

Dawes, D. D. (1987). Improving the Attitudes of Primary Teachers and Students Towards Science by Using a Hands-On Approach. Practicum for Ed.D., Nova University. (ERIC Document Reproduction Service No. ED 294 729).

DeClercq, B., \& Genarro, E. (1987). The Effectiveness of Supplementing the Teaching of the Volume Displacement Concept with Use of an Interactive Computer Simulation. Paper presented at the 60th Annual Meeting of the Association of Research in Science Teaching. Washington, DC.

Deutsch, M. (1962). Cooperation and Trust: Some Theoretical Notes.In M.R. Jones (Ed.), Nebraska Symposium on Motivation (pp. 275-319). Nebraska: University of Nebraska Press.

Diem, R. A. (1985). A Study of Children's Attitudes and Reactions to the New Technology. Social Education, 49, 318-320.

Ediger, M. (1988). Microcomputers in the Science Curriculum. Journal of Computers in Mathematics and Science Teaching, 47-49. 
Edwards, J., Norton, S., Taylor, S., Weiss, M., \& Dusseldorp, R. (1975). How Effective is CAI? A Review of the Research. Educational Leadership, 33, 147-153.

Emihovich, K., \& Miller, G. E. (1988). Effects of Logo and CAl on Black First Graders' Achievement, Reflectivity, and Self-esteem. The Elementary School Journal, 88, 473-487.

Fleming, M. L., \& Malone, M. R. (1983). The Relationship of Student Characteristics and Student Performance in Science as Viewed by MetaAnalysis Research. Journal of Research in Science Teaching, 20, 481-495.

Florida Department of Education (1980). More Hands for Teachers: Report of the Commisioner's Advisory Committee on Instructional Computing. Tallahassee, FL: Office of Educational Technology.

Fowler, E. D. (1989). Raising Spelling Scores through Peer Tutoring and Cooperative Groups. Charleston, SC. (ERIC Document Reproduction Service No. ED 314 726).

Gardner, C. M., Simmons, P. E., \& Simpson, R. D. (1992). The Effects of CAl and Hands-On Activities on Elementary Students' Attitudes and Weather Knowledge. School Science and Mathematics, 92, 334-336.

Gillingham, M. G., \& Guthrie, J. T. (1987). Relationship between CBI and Research on Teaching. Contemporary Educational Psychology, 12, 189 199.

Glass, G. V. (1976). Primary, Secondary, and Meta-analysis of Research. Educational Researcher, 5, 3-8.

Glass, G. V., McGaw, B., \& Smith, M. L. (1981). Meta-analysis in Social Research. Beverly Hills, CA: Sage Publications.

Hall, K. A., \& Grayson, L. P. (Eds.). (1982). Encyclopedia of Educational Research (Vols. 1 and 3). New York: MacMillan and Free Press.353-367, 1329-1336.

Hartley, S. S. (1977). Meta-analysis of the Effects of Individually Paced Instruction in Mathematics. Dissertation Abstracts International, 38 , 4003A.(University Microfilms No. 77-29926). 
Hartshorn, R. L., \& Nelson, R. L. (1990). Hands Cn Science Instruction in the Rural Elementary School: A Strategy to Reduce the High School Dropout Rate. Tucson, AZ. (ERIC Document Reproduction Service No. ED 337 328).

Helgeson, S. L. (1988). Microcomputers in the Science Classroom. Washington, DC: Office of Educational Research and Improvement.

Hider, R. A., \& Rice, D. R. (1988). A Comparison of Instructional Mode on the Attitudes and Achievement of Fifth and Sixth Grade Students in Science. (ERIC Document Reproduction Service No. ED 265 078).

Hofmeister, A. M. (1982). Microcomputers in Perspective. Exceptional Children, 49, 115-121.

Hooper, S., \& Hannafin, M. J. (1988). Cooperative Learning at the Computer: Ability Based Strategies for Implementation. New Orleans, LA. (ERIC Document Reproduction Service No. 295 647).

Jamison, D., Suppes, P., \& Wells, S. (1974). The Effectiveness of Alternative Instructional Media: A Survey. Review of Educational Research, 44, 1-67.

Jaus, H. H. (1977). Activity-Oriented Science: Is it Really that Good? Science and Children, 14, 26-27.

Johnson, D. W., \& Ahlgren, A. (1976). Relationship Between Student Attitudes about Cooperation and Competition and Attitudes Toward Schooling. Journal of Educational Psychology, 68, 92-102.

Johnson, D. W., \& Johnson, R. (1975). Learning Together and Alone: Cooperation, Competition, and Individualization. Englewood Cliffs, NJ: Prentice-Hall.

Johnson, D. W., \& Johnson, R. T. (1974a). Instructional Structure: Cooperative, Competitive, or Individualistic. Review of Educational Research, 44, 213 240.

Johnson, D. W., \& Johnson, R. T. (1974b). The Goal Structure of Open Schools. Journal of Research and Development in Education, 8, 30-47.

Johnson, D. W., \& Johnson, R. T. (1983). Social Interdependence and Perceived Academic and Personal Support in the Classroom. The Journal of Social Psychology, 120, 77-82. 
Johnson, D. W., Johnson, R. T., \& Anderson, D. (1978). Student Cooperative, Competitive, and Individualistic Attitudes, and Attitudes Toward Schooling. The Journal of Psychology, 100, 183-199.

Johnson, D. W., Johnson, R. T., \& Maruyama, G. (1983). Interdependence and Interpersonal Attraction Among Heterogeneous and Homogeneous Individuals: A Theoretical Formulation and a Meta-analysis of the Research. Review of Educational Research, 53, 5-54.

Johnson, D. W., Maruyama, G., Johnson, R.T., Nelson, D., \& Skon, L. (1981). Effects of Cooperative, Competitive, and Individualistic Goal Structures on Achievement: A Meta-Analysis. Psychological Bulletin, 89, 47-62.

Johnson, R. T. (1981). Children's Attitudes Toward Science. Science and Children, 18, 39-41.

Johnson, R. T., \& Johnson, D. W. (1979). Cooperative Learning, Powerful Sciencing. Science and Children, 17, 26-27.

Johnson, R. T., Johnson, D. W., \& Stanne, M. B. (1985). Effects of Cooperative, Competitive, and Individualistic Goal Structures on Computer-Assisted Instruction. Journal of Educational Psychology, 77, 668-677.

Johnson, R. T., Johnson, D. W., \& Stanne, M. B. (1986). Comparison of Computer-Assisted Cooperative, Competitive, and Individualistic Learning. American Educational Research Journal, 23, 382-392.

Johnson, R. T., Johnson, D. W., Scott, L. E., \& Ramolae, B. A. (1985). Effects of Single-Sex and Mixed-Sex Cooperative Interaction on Science Achievement and Attitudes and Cross-Handicap and Cross-Sex Relationships. Journal of Research in Science Teaching, 22, 207-220.

Jones, J. E. (1973). Computer-simulated Experiments in High School Physics and Chemistry. Dissertation Abstracts International, 33 4200A.

Jones, R. M. (1985). Teaming Up. Science and Children, 22, 21-23.

Jones, R. M., \& Steinbrink, J. E. (1989). Using Cooperative Groups in Science Teaching. School Science and Mathematics, 89, 541-551.

Jones, R. M., \& Steinbrink, J. E. (1991). Home Teams: Cooperative Learning in Elementary Science. School Science and Mathematics, 91, 139-143. 
Kulik, C. C., Kulik, J. A., \& Schwalb, B. J. (1986). Effectiveness of Computerbased Adult Education: A Meta-analysis. Journal of Educational Computing Research, 2, 235-252.

Kulik, J. A. (1981). Integrating Findings from Different Levels of Instruction. Paper presented at the annual meeting of the American Educational Research Association. Los Angeles, CA.

Kulik, J. A., \& Bangert-Drowns, R. L. (1983). Effectiveness of Technology in Precollege Mathematics and Science Teaching. Journal of Educational Technology Systems, 12, 137-158.

Kulik, J. A., \& Kulik, C. C. (1987). Review of Recent Research Literature on Computer-based Instruction. Contemporary Educational Psychology, 12, 222-230.

Kulik, J. A., Bangert, R. L., \& Williams, G. W. (1983). Effects of Computer-Based Teaching on Secondary School Students. Journal of Educational Psychology, 75, 19-26.

Kulik, J. A., Bangert, R. L., \& Williams, G. W. (1983). Effects of Computer-based Teaching on Secondary School Students. Journal of Educational Psychology, 75, 19-26.

Kulik, J. A., Kulik, C. C., \& Bangert-Drowns, R. L. (1985). Effectiveness of Computer-Based Education in Elementary Schools. Computers in Human Behavior, 1, 59-74.

Kulik, J. A., Kulik, C. C., \& Cohen, P. A. (1980). Effectiveness of Computer-based College Teaching: A Meta-analysis of Findings. Review of Educational Research, 50, 525-544.

Kyle, W. C. J., Bonnstetter, R. J., \& Gadsden, T. J. (1988). An Implementation Study: An Analysis of Elementary Students' and Teachers' Attitudes Toward Science in Process-Approach vs. Traditional Science Classes. Journal of Research in Science Teaching, 25, 103-120.

Kyle, W. C. J., Bonnstetter, R. J., Gadsden, T. J., \& Shymansky, J. A. (1988). About Hands-on Science. Science and Children, 25, 39-40, 52.

Kyle, W. C. J., Bonnstetter, R. J., McCloskey, S., \& Fults, B. A. (1985). Science through Discovery: Students Love It. Science and Children, 23, 39-41. 
Lazarowitz, R., Hertz, R. L., Baird, J. H., \& Bowlden, V. (1988). Academic Achievement and On-Task Behavior of High School Biology Students Instructed in a Cooperative Small Investigative Group. Science Education, $72,475-487$.

Levin, B. B. (1985). A Dozen Ways to Put Your Classroom Computer to Work...At Last. Curriculum Review, 25, 40-43.

Levin, H. M., \& Meister, G. (1986). Is CAl Cost-Effective? Phi Delta Kappan, 67, 745-749.

Light, P., Foot, T., Colbourn, C., \& McClelland, I. (1987). Collaborative Interactions at the Microcomputer Keyboard. Educational Psychology, 7, 1321.

Logan, T. F. (1986). Cooperative Learning: A View from the Inside. The Social Studies, 77, 123-126.

Lunetta, V. N., \& Blick, D. J. (1973). Evaluation of a Series of Computer-based Dialogues in Introductory Physics. AEDS Journal, 7, 33-42.

Male, M. (1988). Special Magic: Computers, Classroom Strategies, and Exceptional Students. Mountain View, CA: Mayfield Publishing Company.

Messer, D. J., Jackson, A., \& Mohamedali, M. (1987). Influences on Computerbased Problem Solving: Help Facilities, Intrinsic Orientation, Gender and Home Computing. Educational Psychology, 7, 33-46.

Mevarech, Z. R. (1985). The Effects of Cooperative Mastery Learning Strategies on Mathematics Achievement. Journal of Educational Research, 78, 372377.

Niemiec, R. P., Blackwell, M. C., \& Walberg, H. J. (1986). CAI Can Be Doubly Effective. Phi Delta Kappan, 67, 750-751.

Niemiec, R., Samson, G., Weinstein, T., \& Walberg, H. J. (1987). The Effects of Computer Based instruction in Elementary Schools: A Quantitative Synthesis. Journal of Research on Computing in Education, 20, 85-103.

Norton, P. (1985). Problem-Solving Activities in a Computer Environment: A Different Angle of Vision. Educational Technology, 25, 36-41. 
Norton, P., \& Resta, V. (March 1986). Investigating the Impact of Computer Instruction on Elementary Students' Reading Achievement. Educational Technology, 35-41.

Okey, J. R. (1985). The Effectiveness of Computer-based Education. Paper presented at the annual meeting of the National Association for Research in Science, French Lick Springs, IN. (ERIC Document Reproduction Service No. 257 677).

Penick, J. E. (1983). Science as Inquiry. Focus on Excellence. Washington, D.C.: National Science Foundation. (Eric Document Reproduction Service No. ED 243 689).

Perez, E. C., \& White, M. A. (1985). Student Evaluation of Motivational and Learning Attributes of Microcomputer Software. Journal of Computer-Based Instruction, 12, 39-43.

Peterson, P. L., \& Janicki, T. C. (1979). Individual Characteristics and Children's Learning in Large-Group and Small-Group Approaches. Journal of Educational Psychology, 71, 677-687.

Podany, Z. (1990). Software for Middle School Physical Science. Portland, OR: Northwest Regional Educational Lab. (ERIC Document Reproduction Service No. ED 328 444).

Rivers, R. H., \& Vockell, E. (1987). Computer Simulations to Stimulate Scientific Problem Solving. Journal of Research in Science Teaching, 24, 403-415.

Roblyer, M. D., \& King, F. J. (1983). Reasonable Expectations for Computerbased Instruction in Basic Reading Skills. Paper presented at the annual meeting of the Association for Educational Communications. New Orleans, LA.

Roblyer, M. D., Castine, W. H., \& King, F. J. (1988). Assessing the Impact of Computer-Based instruction: A Review of Recent Research (Special Issue). Computers in the Schools, 5 .

Rupe, V. S. (1986). A Study of Computer-Assisted Instruction: Its Uses, Effects, Advantages, and Limitations. IN: Indiana University Exit Project. (ERIC Document Reproduction Service No. ED 282 513). 
Rupley, W. H., \& Chevrette, P. (1983). Computer Assisted Reading Instruction: A Promising Tool for Enhancing Teacher Effectiveness. Reading World, 22, 236-240.

Samson, G. E., Niemiec, R., Weinstein, T., \& Walberg, H. J. (1985). Effects of Computer-based Instruction on Secondary School Achievement: $A$ Quantitative Synthesis. Paper presented at the annual meeting of the American Educational Research Assoc., Chicago, IL.

Sharan, S. (1980). Cooperative Learning in Small Groups: Recent Methods and Effects on Achievement, Attitudes, and Ethnic Relations. Review of Educational Research, 50, 241-271.

Shaw, E. L. J., \& Okey, J. R. (1985). Effects of Miicrocomputer Simulations on Achievement and Attitudes of Middle School Students. French Lick Springs, IN. (ERIC Document Reproduction Service No. ED 255 389).

Sheingold, K., Kane, J. H., \& Endreweit, M. E. (1983). Microcomputer Use in Schools: Developing a Research Agenda. Harvard Educational Review, $53,412-433$.

Showalter, V. M. (1984). Conditions for Good Science Teaching. Washington, DC: National Science Teachers Association. (ERIC Document Reproduction Service No. 245 916).

Shymansky, J. A. (1989). What Research Says about ESS, SCIS, and SAPA. Science and Children, 33-35.

Shymansky, J. A., Hedges, L. V., Woodworth, G., \& Berg, C. (1986). A Study of Uncertainties in the Meta-analysis of Research on the Effectiveness of "New" Science Curricula. Paper presented at the annual meeting of the National Association for Research in Science. San Francisco, CA.

Shymansky, J. A., Kyle, K. C. J., \& Alport, J. M. (1982). How Effective Were the Hands-On Programs of Yesterday. Science and Children, 20, 14-15.

Simmons, P. E., \& Simpson, R. D. (1992). The Effects of CAI and Hands-On Activities on Elementary Students' Attitudes and Weather Knowledge. School Science and Mathematics, 92, 334-336.

Simpson, J. (1986). Computers and Collaborative Work Among Students. Educational Technology, 26, 37-44. 
Simpson, R. D., \& Oliver, J. S. (1985). Attitude Toward Science and Achievement Motivation Profiles of Male and Female Science Students in Grades Six Through Ten. Science Education, 69, 511-526.

Simpson, R. D., \& Oliver, J. S. (1990). A Summary of Major Influences on Attitude Toward and Achievement in Science Among Adolescent Students. Science Education, 74, 1-18.

Slavin, R. E. (1980). Cooperative Learning. Review of Educational Research, $50,315-342$.

Slavin, R. E. (1983b). When Does Cooperative Learning Increase Student Achievement? Psychological Bulletin, 94, 429-445.

Slavin, R. E. (1984). Meta-analysis lin Education: How has it been used? Educational Researcher, 13, 6-15.

Slavin, R. E. (1987). Best-evidence Synthesis: Why Less is More. Educational Researcher, 16, 15-16.

Slavin, R. E. (1987). Cooperative Learning and Individualized Instruction. Arithmetic Teacher, 14-16.

Slavin, R. E. (1987). Cooperative Learning: Where Behavioral and Humanistic Approaches to Classroom Motivation Meet. The Elementary School Joumal, 88, 29-37.

Slavin, R. E. (1987). Developmental and Motivational Perspectives on Cooperative Learning: A Reconciliation. Child Development, 58, 1161 . 1167.

Slavin, R. E. (1987a). Cooperative Learning and the Cooperative School. Educational Leadership, 45, 7-13.

Talmage, H., Pascarella, E. T., \& Ford, S. (1984). The Influence of Cooperative Learning Strategies on Teacher Practices, Student Perceptions of the Learning Environment, and Academic Achievement. American Educational Research Journal, 21, 163-179.

Tamir, P. (1985/86). Current and Potential Uses of Microcomputers in Science Education. Journal of Computers in Mathematics and Science Teaching, 2, 18-28. 
Tanner, D. E. (1984). Horses, Carts, and Computers in Reading: A Review of Research. Computers, Reading, and Language Arts, 2, 35-38.

Thomas, D. B. (1979). The Effectiveness of CAI in Secondary Schools. AEDS Journal, 103-106.

Thompson, M. E. (1983). Beyond the Computer: Reading as a Process of Intellectual Development. Minneapolis, MN. (ERIC Document Reproduction Service No. ED 236 555).

Vargas, J. S. (1986). Instructional Design Flaws in Computer-Assisted Instruction. Phi Delta Kappan, 67, 738-744.

Vinsoninaler, J. F., \& Bass, R. K. (1972). A Summary of Ten Major Studies on CAl Drill and Practice. Educational Technology, 29-32.

Vockell, E. L., \& Rivers, R. (1984a). Computerized Science Simulations: Stimulus to Generalized Problem-solving Capabilities. Paper presented at the annual meeting of the American Educational Research Association. New Orleans, LA.

Vockell, E. L., \& Rivers, R. (1984b). Computer Simulations to Stimulate Problem Solving Skills. Final Report to the National Science Foundation.

Vorsino, W. S. (1990). Improving Science Intruction for First Grade Students through Curriculum Development. Practicum for Ed.D., Nova University. (ERIC Document Reproduction Service No. ED 329 431).

Walkington, P., \& Babcock, E. (1984). Educational Computing and the Gifted Child. Teaching Exceptional Children, 16, 266-269.

Waugh, M. L. (1985). Proposed Directions for Research in Computer-Based Education. French Lick Springs, IN. (ERIC Document Reproduction Service No. ED 257 627).

Webb, N. M. (1982). Peer Interaction and Learning in Cooperative Small Groups. Journal of Educational Psychology, 74, 642-655.

Webb, N. M. (1984). Microcomputer Learning in Small Groups: Cognitive Requirements and Group Processes. Joumal of Educational Psychology, 76, 1076-1088. 
Webb, N. M. (1985b). Student Interaction and Learning in Small Groups: A Research Summary. In R. Slavin, S. Sharan, S. Kagan, R.H. Lazarowitz, C. W. Webb, \& R. Schmuck (Eds.), Learning to Cooperate, Cooperating to Learn, New York: Plenum Press (pp.147-172).

Webb, N. W. (1986). Learning Centers to Supplement the Second Grade Science Program. Practicum for Ed.D., Nova University. (ERIC Document Reproduction Service No. 281 754).

Weinstein, R., Boulanger, D., \& Walberg, H. J. (1982). Science Curriculum Effects in High School: A Quantitative Synthesis. Journal of Research in Science Teaching, 19, 511-522.

Willett, J. B., Yamashita, J. M., \& Anderson, R. D. (1983). A Meta-analysis of Instructional Systems Applied in Science Teaching. Journal of Research in Science Teaching, 20, 405-417.

Winkler, J. D., \& And Others. (1982). Successful Use of Microcomputers in Classroom Instruction. Wilmington, DE. (ERIC Document Reproduction Service No. ED 247 911).

Wise, K. C., \& Okey, J. R. (1983). A Meta-Analysis of the Effects of Various Science Teaching Strategies on Achievement. Journal of Research in Science Teaching, 20, 419-435.

Yager, R. E. (1986). What's Wrong with School Science? The Science Teacher, 145-146.

Yager, R. E., \& Yager, S. O. (1984). The Effect of Schooling Upon the Understanding of Selected Science Terms. Joumal of Research in Science Teaching, 22, 359-364.

Yore, L. D. (1986). The Effects of Lesson Structure and Cognitive Style on the Science Achievement of Elementary School Children. Science Education, $70,461-471$.

Zintz, M., \& Maggart, Z. (1984). The Reading Process: The Teacher and the Learner. Dubuque, IA: Wm. C. Brown Publishers. 
Name:

Room Number:

Team Number:

\section{PRE-QUESTIONNAIRE}

1. I enjoy doing hands-on science experiments.
A. strongly agree
B. agree
C. undecided
D. disagree
E. strongly disagree

2. I enjoy using the computer.
A. strongly agree
B. agree
C. undecided
D. disagree
E. strongly disagree

3. When doing science experiments, I prefer:
A. working alone
B. working with a partner of my choice
C. working with a group of my choice
D. any of the above

4. When using the computer, I prefer:
A. working alone
B. working with a partner of my choice
C. working with a group of my choice
D. any of the above 


\section{PRE-QUESTIONNAIRE}

5. I feel that my group will work successfully together.

$\begin{array}{ll}\text { A. } & \text { strongly agree } \\ \text { B. } & \text { agree } \\ \text { C. } & \text { undecided } \\ \text { D. } & \text { disagree } \\ \text { E. } & \text { strongly disagree }\end{array}$

6. I think my group would be just as successfui without me.
A. strongly agree
B. agree
C. undecided
D. disagree
E. strongly disagree 


\section{PRE-QUESTIONNAIRE}

7. A strong wind has blown a heavy branch onto your driveway. You must figure out a way to move the branch so the car can be taken out of the garage, and you can be driven to your best friend's party.

Use any combination of the following objects to move the branch. Use drawings and/or words to explain what you plan to use and why.

You may use any combination of the objects below.

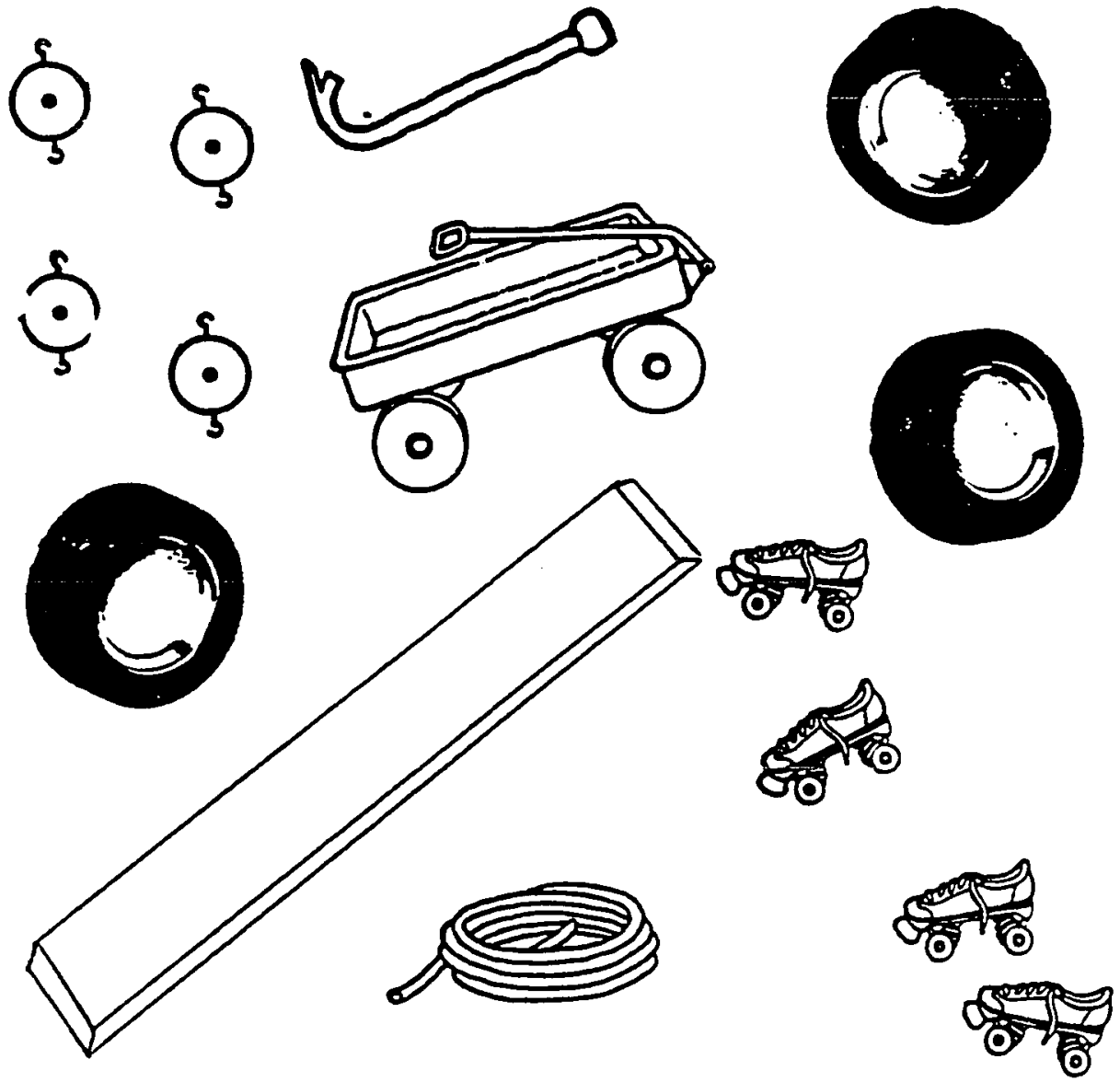




\section{PRE-QUESTIONNAIRE}

PLAN 1: You may use any of the objects on the previous page to move the branch. Use drawings and/or words to explain what you plan to use and why.

PLAN 2: Come up with a second strategy for moving the branch. Use drawings and/or words to explain what objects you plan to use and why. 


\section{PRE-QUESTIONNAIRE}

8. Give one good reason why it is important for people to know how to set up pulley systems.

9. Look carefully at these pictures of pulley systems. Circle any pulley system that will work properly.

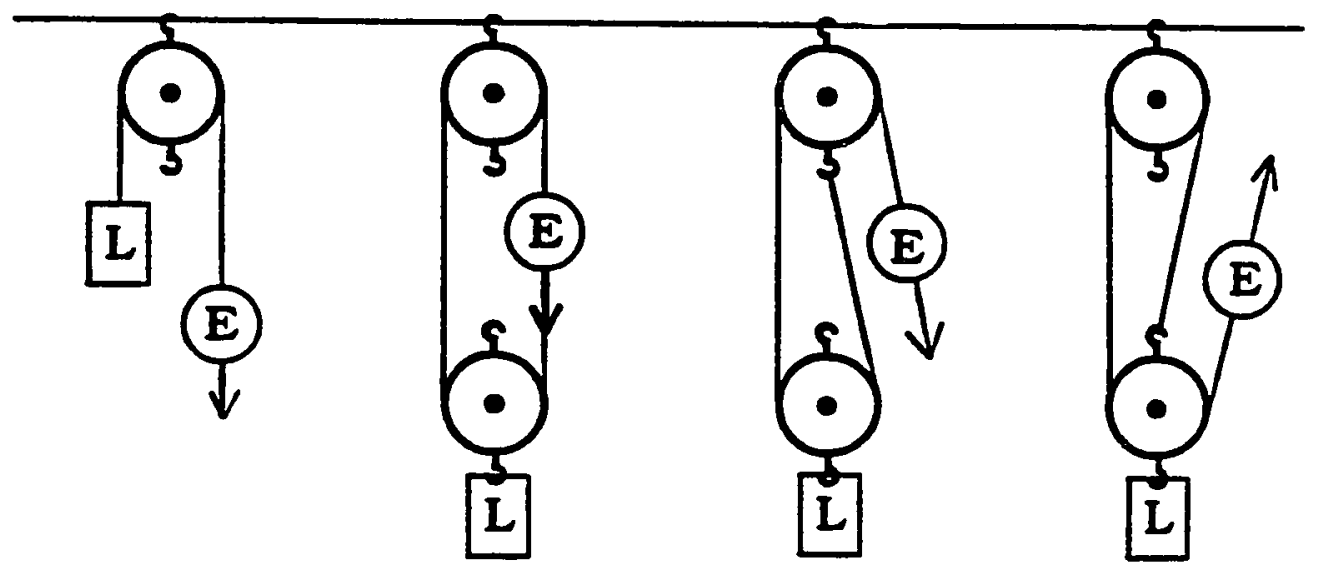


Name:

Room Number:

Team Number:

\section{POST-QUESTIONNAIRE}

1. I enjoyed doing the hands-on experiments from the F.O.S.S.: Levers and Pulleys kit.
A. strongly agree
B. agree
C. undecided
D. disagree
E. strongly disagree

2. I enjoyed using the computer software Miner's Cave.
A. strongly agree
B. agree
C. undecided
D. disagree
E. strongly disagree

3. I enjoyed working with my group.
A. strongly agree
B. agree
C. undecided
D. disagree
E. strongly disagree

4. When doing science experiments, I prefer:
A. working alone
B. working with a partner of my choice
C. working with a group of my choice
D. any of the above 


\section{POST-QUESTIONNAIRE}

5. When using the computer, I prefer:
A. working alone
B. working with a partner of my choice
C. working with a group of my choice
D. any of the above

6. I feel that my group worked successfully together.
A. strongly agree
B. agree
C. undecided
D. disagree
E. strongly disagree

7. I think my group would have been just as successful without me.
A. strongly agree
B. agree
C. undecided
D. disagree
E. strongly disagree

8. Number the following items from 1 to 3 depending on how well they helped you understand what simple machines are and how they work. Number 1 would be most helpful.

Miner's Cave computer program

hands-on pulley experiments

working with a group 


\section{POST-QUESTIONNAIRE}

9. A strong wind has blown a heavy branch onto your driveway. You must figure out a way to move the branch so the car can be taken out of the garage, and you can be driven to your best friend's party.

Use any combination of the following objects to move the branch. Use drawings and/or words to explain what you plan to use and why.

You may use any combination of the objects below.

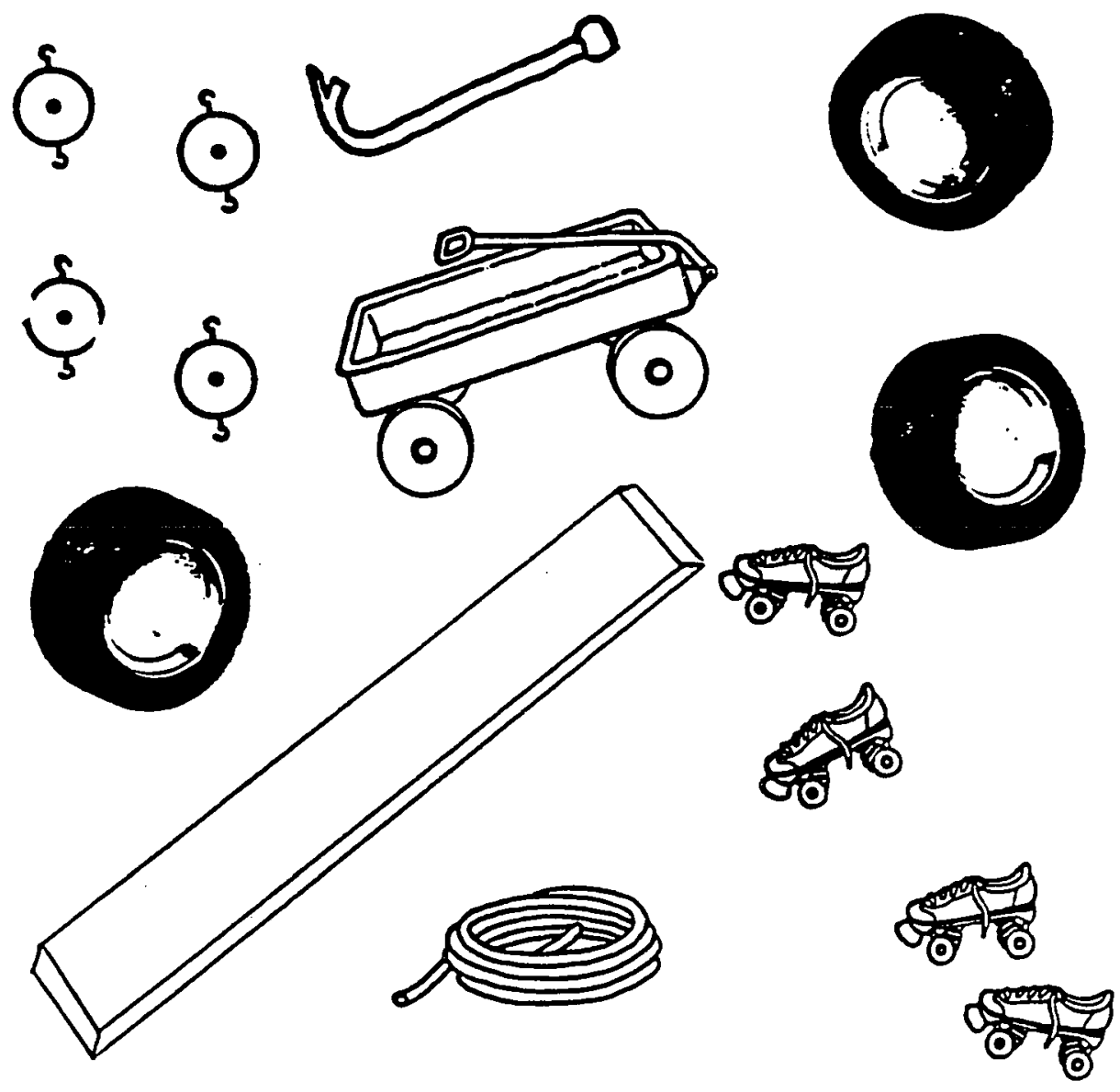




\section{POST-QUESTIONNAIRE}

PLAN 1: You may use any of the objects on the previous page to move the branch. Use drawings and/or words to explain what you plan to use and why.

PLAN 2: Come up with a second strategy for moving the branch. Use drawings and/or words to explain what objects you plan to use and why. 


\section{POST-QUESTIONNAIRE}

10. Give one good reason why it is important for people to know how to set up pulley systems.

11. Look carefully at these pictures of pulley systems. Circle any pulley system that will work properly.

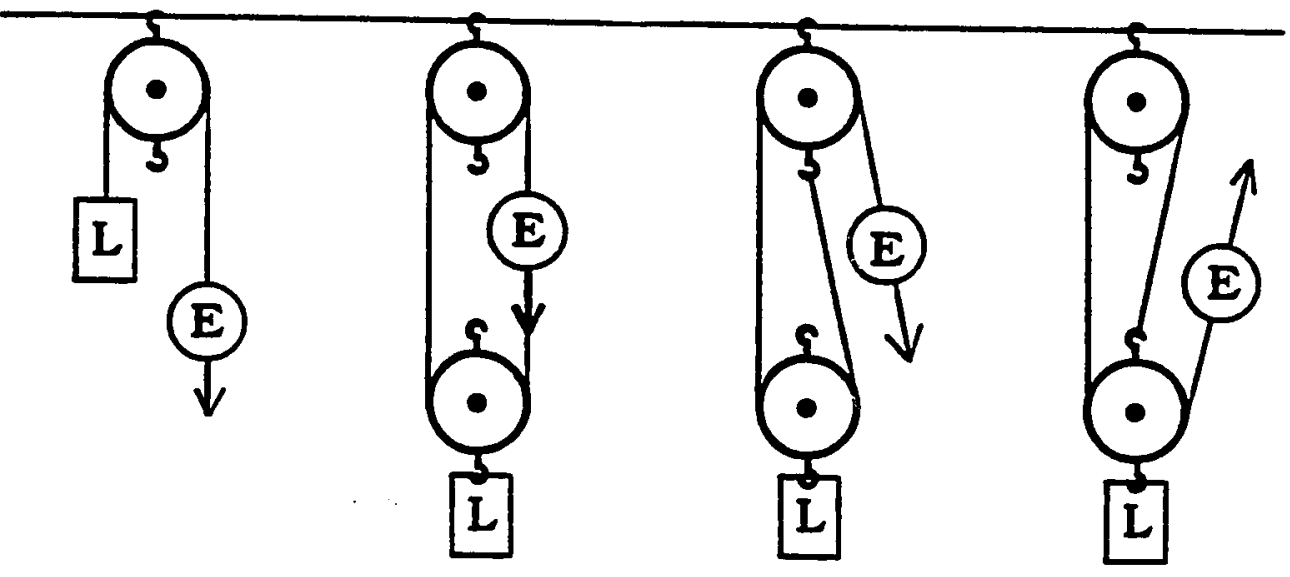

12. What generally happens to the effort needed to lift a load as the number of pulleys in the system increases. 


\section{POST-QUESTIONNAIRE}

13. The two children shown weigh exactly the same. CIRCLE THE PICTURE which best shows how the seesaws would look when they stop moving. Explain your choice.

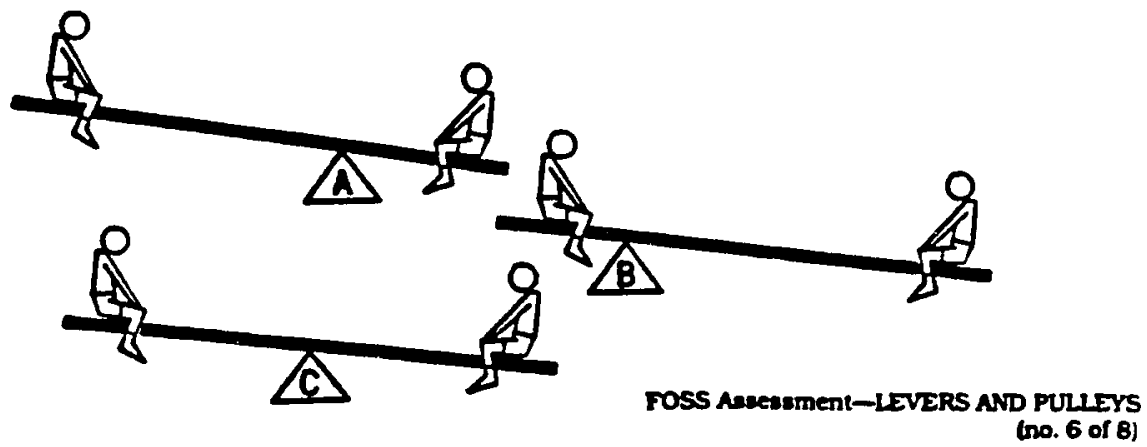

